\title{
Stepped fans and facies-equivalent phyllosilicates in Coprates Catena, Mars
}

\author{
P.M. Grindrod ${ }^{\mathrm{a}, *}$, N.H. Warner ${ }^{\mathrm{b}}$, D.E.J. Hobley ${ }^{\mathrm{c}}$, C. Schwartz $^{\mathrm{d}}$, S. Gupta ${ }^{\mathrm{e}}$ \\ a Department of Earth Sciences, Natural History Museum, Cromwell Road, London SW7 5BD, UK \\ ${ }^{\mathrm{b}}$ Department of Geological Sciences, State University of New York at Geneseo, Geneseo, NY, USA \\ 'School of Earth and Ocean Sciences, Cardiff University, Cardiff, UK \\ det Propulsion Laboratory, California Institute of Technology, Pasadena, CA, USA \\ e Department of Earth Science and Engineering, Imperial College London, London, UK
}

\section{A R T I C L E I N F O}

\section{Article history:}

Received 5 March 2015

Revised 5 October 2017

Accepted 17 October 2017

Available online $\mathrm{xxx}$

\begin{abstract}
A B S T R A C T
Stepped fan deposits and phyllosilicate mineralogies are relatively common features on Mars but have not previously been found in association with each other. Both of these features are widely accepted to be the result of aqueous processes, but the assumed role and nature of any water varies. In this study we have investigated two stepped fan deposits in Coprates Catena, Mars, which have a genetic link to lighttoned material that is rich in Fe-Mg phyllosilicate phases. Although of different sizes and in separate, but adjacent, trough-like depressions, we identify similar features at these stepped fans and phyllosilicates that are indicative of similar formation conditions and processes. Our observations of the overall geomorphology, mineralogy and chronology of these features are consistent with a two stage formation process, whereby deposition in the troughs first occurs into shallow standing water or playas, forming fluvial or alluvial fans that terminate in delta deposits and interfinger with interpreted lacustrine facies, with a later period of deposition under sub-aerial conditions, forming alluvial fan deposits. We suggest that the distinctive stepped appearance of these fans is the result of aeolian erosion, and is not a primary depositional feature. This combined formation framework for stepped fans and phyllosilicates can also explain other similar features on Mars, and adds to the growing evidence of fluvial activity in the equatorial region of Mars during the Hesperian and Amazonian.
\end{abstract}

(C) 2017 Published by Elsevier Inc.

\section{Introduction}

Evidence of the history of water on Mars is recorded in the sedimentary characteristics and stratigraphy of sedimentary rock exposed at the surface. Through an integrated physical and geochemical analysis of this record, it is possible to evaluate the climate history and habitability potential of Mars (e.g. Grotzinger et al., 2011). Studies of fluvial sedimentology and mineralogy have long been fundamental to revealing paleoenvironmental conditions of the planet (e.g. Masurksy, 1973; Sharp and Malin, 1975; Baker and Partridge, 1986; Tanaka, 1986; Craddock and Maxwell, 1993) and will continue to be essential with the acquisition of higher resolution data. Of particular interest are sedimentary fans associated with channel features, as they can in principle be used to determine whether subaerial or subaqueous conditions were prevalent at the time of formation (e.g. Moore and Howard, 2005; Fassett

\footnotetext{
* Corresponding author.

E-mail address: p.grindrod@nhm.ac.uk (P.M. Grindrod).
}

and Head, 2008; Di Achille and Hynek, 2010). However, difficulties remain in determining whether a particular fan deposit on Mars is a subaerial alluvial fan (e.g. Jerolmack et al., 2004; Moore and Howard, 2005; Di Achille et al., 2006; Williams et al., 2006, 2011) or a subaqueous (lacustrine) delta fan (e.g. Cabrol and Grin, 1999; Ori et al., 2000; Fassett and Head, 2005; Weitz et al., 2006; Pondrelli et al., 2008; Rice et al., 2011, 2013; Schon et al., 2012; DiBiase et al., 2013). Here we aim to contribute toward this debate by examining a specific subset of uniquely stepped fans on Mars.

Although previous studies have investigated stepped fans on Mars, they disagree on the exact formation mechanisms responsible. Earlier studies agreed that one of our study sites contains a terminal deposit of fluvial activity along an incised bedrock channel, but proposed differing end-member mechanisms to account for the formation of the fan and the aqueous history of the trough. Di Achille et al. (2006) argued for an alluvial, sheetflooddominated deposition, whereas Weitz et al. (2006) preferred a deltaic deposition process. More generally, by analogy with flume experiments, Kraal et al. (2008) and de Villiers et al. (2013) suggest that all stepped fans on Mars are the result of single, rapid 
(tens of years) depositional events in a system characterized by rising base level water. Other possible mechanisms for the generation of stepped fans are summarized by Irwin et al. (2005), and include primary methods such as wave erosion (Ori et al., 2000; Cabrol and Grin, 2001) and secondary methods such as compressive stress-driven slumping (Malin and Edgett, 2003) and aeolian erosion (Irwin et al., 2005). The implications of these different scenarios are important because they determine whether there was ever a standing body of water in the trough, and ultimately whether these deposits can be used to support or refute wider hypotheses about the timing of fluvial (e.g. Irwin et al., 2005) and aqueous alteration (e.g. Bibring et al., 2006) processes.

In this study, we utilize new data sets to address the formation of two stepped fans in separate closed troughs in Coprates Catena, in south-east Valles Marineris. These features are of particular interest because of the previous identification of phyllosilicate material in light-toned deposits (LTDs) in one of the study troughs, which is itself likely to be Hesperian in age (Grindrod et al., 2012). Our aim is to not only help understand how the stepped fans formed in our study region, but also to determine whether these features are linked to phyllosilicate-bearing deposits. This approach allows us to determine the role and nature of water in this region, and by extension, can help place the inferred paleoenvironments into the broader context of the history of water on Mars (e.g. Bibring et al., 2006). Our approach combines a coupled analysis of surface texture (from imagery) and form (from elevation models) across the study sites with hyperspectral processing of CRISM data and crater counting. Together, these data allow us to synthesize the sedimentology, mineralogy, geomorphology, and age of features into a clearer view of the likely environments in which they formed.

\section{Data and methods}

All data used in this study were obtained through the NASA Planetary Data System (PDS) and processed using standard techniques, which are outlined here. Where possible we have combined different data sets in a Geographical Data System (GIS) to aid analysis and interpretation. Specific data sets used include topography and imagery from Mars Global Surveyor MOLA (Smith et al., 1999), Mars Express HRSC (Jaumann et al., 2007), and Mars Reconnaissance Orbiter CTX (Malin et al., 2007), CRISM (Murchie et al., 2007), and HiRISE (McEwen et al., 2007). The exact processing chain differed according to data type.

\subsection{Visible wavelength images and digital terrain models}

Visible wavelength images were processed using standard calibration and map-projection routines in the Integrated Software for Imagers and Spectrometers (ISIS), freely-available through the United States Geological Survey (USGS). The list of images used in this study for both fan systems is given in Table 1. Where image coverage allowed, we prepared HiRISE and CTX digital terrain models (DTMs) using stereo pairs and standardized techniques in ISIS and the commercial image analysis software SOCET SET (Kirk et al., 2008). The resolution of our HiRISE and CTX stereo DTMs are 1 and $20 \mathrm{~m} /$ pixel respectively, with accompanying orthorectified images also produced at similar resolutions and at 0.25 and $6 \mathrm{~m} /$ pixel respectively. Using previous methods (Kirk et al., 2003, 2008; Okubo, 2010), we estimate the vertical precision of our CTX stereo DTM (images P05_003157_1650 and P08_003658_1658) at Fan 1 as $2.4 \mathrm{~m}$, and our HiRISE stereo DTM (images ESP_016857_1645 and ESP_017569_1645) at Fan 2 as $0.31 \mathrm{~m}$. These stereo DTMs were used to carry out structural analysis using the commercial software ORION, which has been successfully used with martian topographic data sets in previous studies (e.g. Fueten et al., 2008,
2010; Okubo, 2010; Grindrod et al., 2012). We also produced an additional CTX stereo DTM at Fan 2 (images B20_017569_1647 and G04_019903_1658) that, due to the small stereo convergence angle resulting in poor vertical precision, we did not use in any structural analysis. In addition, we also produced a HiRISE stereo DTM at Fan 1 (images ESP_022949_1650 and ESP_030518_1650) that has good vertical precision $(0.15 \mathrm{~m})$ but which only covers half of the fan width, and so was not used in any structural analysis.

\subsection{Hyperspectral data}

CRISM data were processed and analyzed using standard techniques described in previous studies (e.g. Murchie et al., 2007, 2009a; Ehlmann et al., 2009) and outlined here. CRISM coverage is limited in our two study regions. In the Fan 1 region, the CRISM observation FRT0007203 covers the fan deposit but is not of sufficient observation quality to allow analysis. Another CRISM observation (FRT00011DF2) covers related deposits in the Fan 1 trough and was described in detail in a previous study (Grindrod et al., 2012). For the Fan 2 region, we analyzed one full-resolution CRISM image that covers the base of the trough and related light-toned deposits (FRT0001FB4F), and one half-resolution image that extends to the plains outside the trough (HRL0001B8AE). We used the commercial software ENVI with the CRISM Analysis Toolkit (CAT) v7.1.1 plug-in (Morgan et al., 2009) to process and analyze the CRISM data according to standard protocols. In brief, we converted the CRISM data to $\mathrm{I} / \mathrm{F}$ before applying a photometric conversion to correct for variations in illumination and an atmospheric correction using the volcano-scan method to minimize atmospheric $\mathrm{CO}_{2}$ band absorptions (McGuire et al., 2009). The CRISM image was then destriped and de-spiked to remove noise and large spikes inherent in the instrument (e.g. Parente, 2008). Spectral parameters, which highlight visible and near-infrared spectral features in some mineral types (Pelkey et al., 2007) were produced and flattened to reduce the effect of the "spectral smile" (Murchie et al., 2007). These spectral parameter summary products were then used for mapping of different mineralogical units. Spectra of target units were taken both as a $3 \times 3$ pixel averages and as regions of interest (RoIs) typically approximately $100-200$ pixels in size. These spectra were taken from the map-projected image to aid later GIS co-registration with other data sets, but were checked in the nonmap projected data to ensure there were no map-projection artifacts. Due to difficulty in selecting a spectrally-bland region and to avoid introducing spectral artifacts, we follow previous studies (e.g. Bishop et al., 2009; Ehlmann et al., 2009; Massé et al., 2012; Sefton-Nash et al., 2012) in using unratioed CRISM spectra in our analyses. This method means that there is a larger degree of instrumental and atmospheric noise in our spectra than would be present in ratioed spectra (Bishop et al., 2009). Finally, these spectra were compared to laboratory spectra taken from the CRISM Spectral Library (Murchie et al., 2007).

\subsection{Crater counting}

We used two different methods of crater counting to determine relative and absolute crater retention ages for different surfaces. First, in an attempt to identify any possible differences in small crater retention between fan surfaces, we mapped every crater with a diameter greater than $1 \mathrm{~m}$ that was identifiable in HiRISE images covering the fan surfaces. Rather than map craters over the entire fan surface we took a longitudinal profile through the fans and counted all craters within $500 \mathrm{~m}$ of this line, giving an effective width of $1 \mathrm{~km}$. As in a previous study (Grindrod et al., 2012) we used these crater maps in an attempt to identify different crater retention surfaces, rather than derive absolute ages. Second, as the fan deposits themselves are too small to derive reliable 
Table 1

List of images used in this study for each fan system.

\begin{tabular}{|c|c|c|c|c|}
\hline Instrument & Image number & Stereo pair image number & DTM resolution (m/pixel) & DTM vertical precision $(\mathrm{m})$ \\
\hline \multicolumn{5}{|l|}{ Fan 1} \\
\hline HRSC & H1929_0000 & & & \\
\hline \multirow[t]{2}{*}{ CTX } & P05_003157_1650 & P08_003658_1658 & 20 & 2.4 \\
\hline & P08_004080_1651 & & & \\
\hline \multirow[t]{2}{*}{ HiRISE } & PSP_004924_1650 & & & \\
\hline & ESP_022949_1650 & ESP_030518_1650 & 1 & 0.15 \\
\hline \multicolumn{5}{|l|}{ Fan 2} \\
\hline HRSC & H1918_0000 & & & \\
\hline \multirow[t]{4}{*}{ CTX } & B16_016079_1622 & & & \\
\hline & B20_017569_1647 & G04_019903_1658 & 20 & 23.5 \\
\hline & G05_020259_1615 & & & \\
\hline & P14_006704_1658 & & & \\
\hline \multirow[t]{2}{*}{ HiRISE } & ESP_016857_1645 & ESP_017569_1645 & 1 & 0.31 \\
\hline & ESP_019270_1645 & & & \\
\hline \multirow[t]{2}{*}{ CRISM } & FRT0001FB4F & & & \\
\hline & HRL0001B8AE & & & \\
\hline
\end{tabular}

absolute crater-derived ages, we used CTX images of the surrounding terrain to derive absolute age estimates. As the Coprates Catena troughs cut through these plain deposits, these crater counts then offer a maximum age for features that postdate trough formation, including the fan deposits. Model ages were determined for different surfaces approximately $600-26,000 \mathrm{~km}^{2}$ in area, using standard chronology and production functions on cumulative frequency histograms (Hartmann and Neukum, 2001; Ivanov, 2001).

\section{Observations}

\subsection{Geologic context}

Our study region is located in the Coprates Catena region of South-East Valles Marineris (Fig. 1). We investigate two sediment fan systems, hereafter named Fan 1 and Fan 2 that are approximately $75 \mathrm{~km}$ apart, and located in separate but adjacent closed troughs that are about $80 \mathrm{~km}$ south of the main Coprates Chasma rift system. Fan 1 is the most westerly of our study sites, lying on the floor of a west-east oriented closed trough that likely formed by collapse and/or extension during the opening of the Valles Marineris rift system. The trough is $15 \times 47 \mathrm{~km}$ and has a maximum depth of $\sim 3.4 \mathrm{~km}$. Fan 2 lies on the floor of another closed trough, which is approximately $21 \times 47 \mathrm{~km}$ with a maximum depth of about $3.5 \mathrm{~km}$. Both troughs show valley features eroded into the surrounding highland plains that appear to terminate in the trough depressions. The channel at Fan 1 heads from the surrounding plains without a discernable source as a broad $(\sim 1 \mathrm{~km})$ and shallow $(\sim 100 \mathrm{~m})$ valley, obvious in the MOLA topography. Along profile, the channel becomes a single incised sinuous bedrock canyon that both deepens (up to $1 \mathrm{~km}$ deep) and widens ( $4 \mathrm{~km}$ wide) over a distance of $40 \mathrm{~km}$. A preserved amphitheatershaped inner knickpoint, visible in THEMIS and CTX imagery, is present on the floor of the canyon approximately $11 \mathrm{~km}$ upstream from the where the canyon debouches into the trough. The headwall of the knickpoint is $\sim 1.2 \mathrm{~km}$ wide and $250 \mathrm{~m}$ tall, and likely indicates that the bedrock canyon formed by a process of headward bedrock incision by water where the headwall migrated upstream from the trough margin. By comparison, the channel at Fan 2 is less discernible in topography data despite being identifiable through light-toned deposits for approximately $40 \mathrm{~km}$.

The closed troughs that contain our study fans are assumed to have formed as part of the wider formation of this part of Valles Marineris, based on the results of previous studies (e.g. Schultz, 1991, 1998; Andrews-Hanna, 2012a, 2012b, 2012c). The formation time of these troughs is important as it serves as a marker throughout our study, allowing relative age relationships from small-scale studies within the troughs to be extended to absolute timescales and the wider geological picture. The majority of the plains in which the Coprates Catena troughs formed have previously been identified as Late Hesperian in age, although the area immediately south of our study troughs was also previously dated to the Noachian (Scott and Tanaka, 1986). The wider Coprates Catena depressions in this region are probably a relatively late stage event in the formation of Valles Marineris, possibly forming as late as the Early Amazonian (Schultz, 1998). In addition to the formation time of the troughs, the chemistry of material in the canyon walls and plains surrounding the wider Coprates region are also pertinent to the deposits found in the troughs themselves in terms of understanding the possible provenance and environmental context of the mineral signatures identified in the troughs. Previous work has identified the presence of phyllosilicate minerals in light-toned deposits exposed in this region (Flahaut et al., 2012; Le Deit et al., 2012). In contrast, LTDs found in plains surrounding other areas of Valles Marineris region have been found to be dominated by opaline silica and sulfate mineralogies (Weitz et al., 2010).

\subsection{Paleogeomorphology and structure}

Although of different sizes, both fans share some similar characteristics that are outlined in Fig. 2. Both fans are made up of layered sedimentary rock that extend from the termination of a bedrock channel to the base of a closed trough. The fan deposits can be sub-divided two distinct stratigraphic units based on gross layering characteristics and geometry: a stepped unit and a ridged unit.

The trough floors contain a variety of geomorphic features, such as slump blocks, layered material, light-toned deposits, mantling material, impact craters and collapse features. The presence of similar features and stratigraphic unit types in both troughs suggests the possibility of contiguity of morphology and processes between the troughs.

Fan 1 is characterized by a distinctive stepped appearance, with at least 24 major steps visible at CTX resolution (Fig. 3). Each step typically consists of a relatively flat-lying terrace (width of order 10 to $100 \mathrm{~m}$ ) separated by a steeper (up to $\sim 20-30^{\circ}$ at CTX stereo DTM resolution) riser (width of order $1-10 \mathrm{~m}$ ). Although it is not possible to identify each step boundary exactly, individual step widths vary from less than $50 \mathrm{~m}$ to approximately $1 \mathrm{~km}$ in plan view. These steps are well defined throughout the majority of the length of the fan and the $\sim 130^{\circ}$ fan arc. The best-defined steps occur across the central part of the fan, while some definition is lost toward the western and eastern edges of the fan. In some cases 


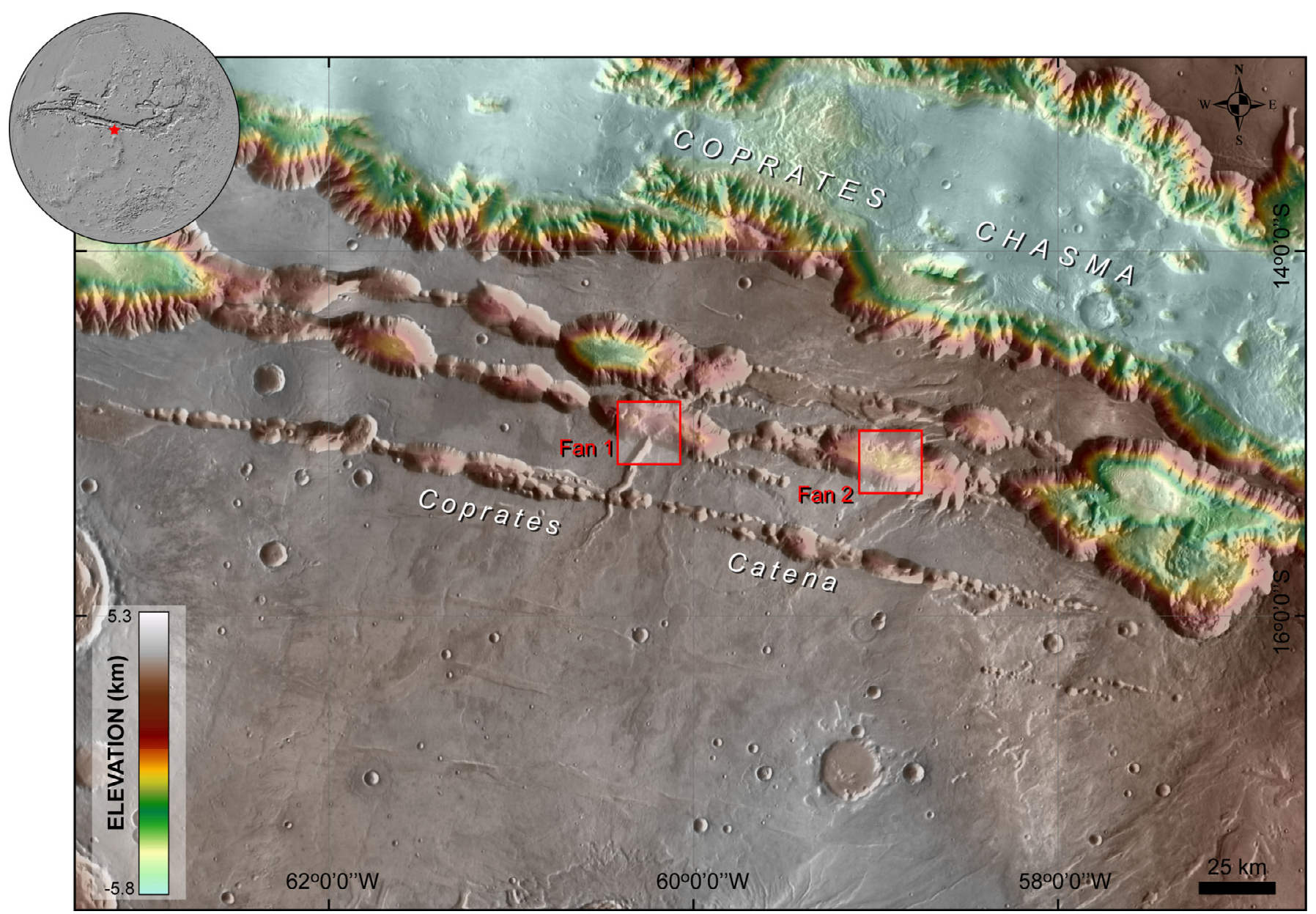

Fig. 1. Location of study area. Inset shows the SE Valles Marineris region, with the colored box highlighting the area of the main image. The main image shows the regional context for the study area, with the boxes outlining the locations of Fans 1 and 2. Base image is colorized MOLA hillshade. (For interpretation of the references to colour in this figure legend, the reader is referred to the web version of this article.)
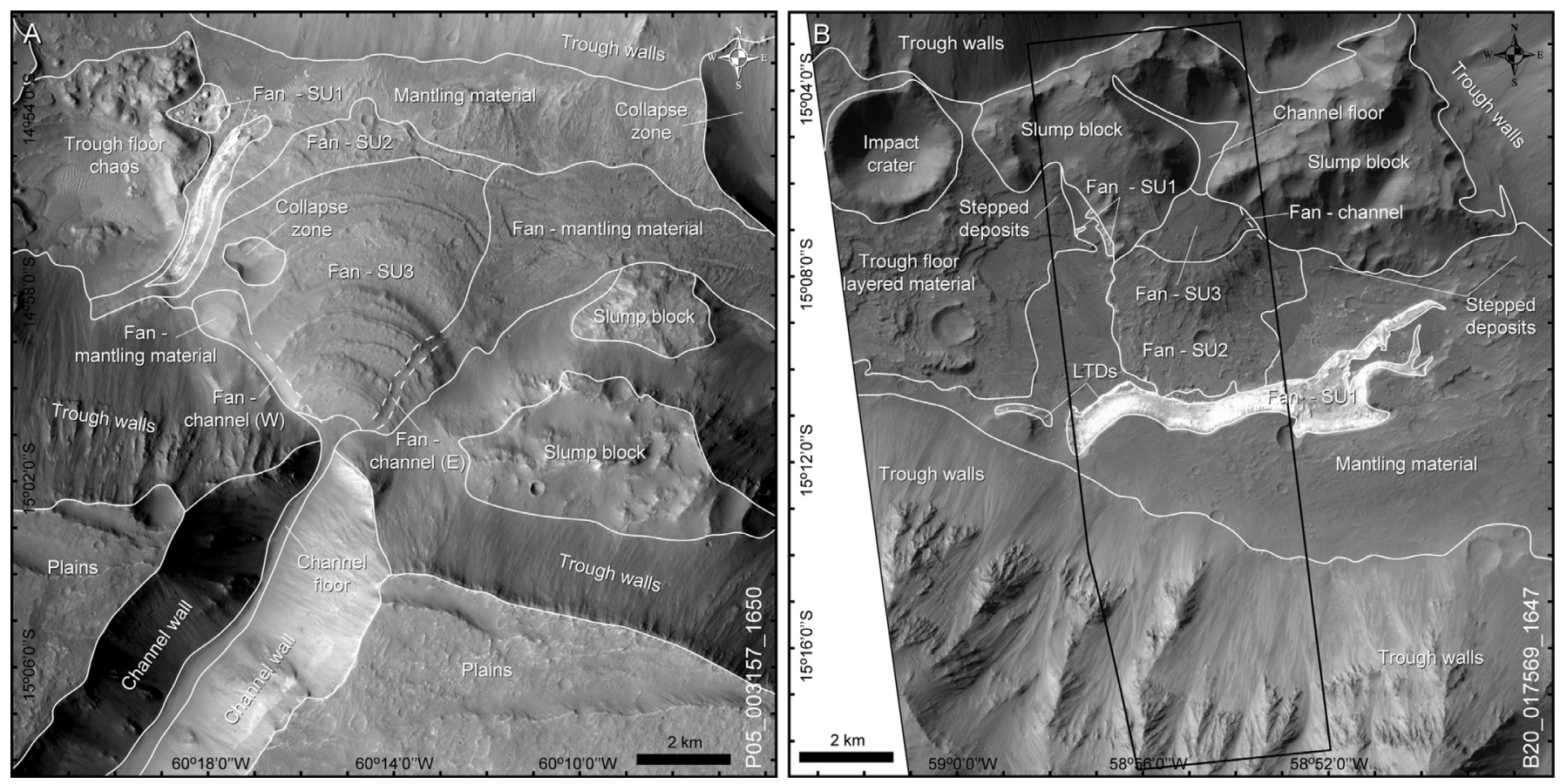

Fig. 2. Local context of the two study fans and geomorphologic units. CTX images of (a) Fan 1 and (b) Fan 2 with the location of the HiRISE stereo DTM area outlined in black. Fan Stratigraphic Units (SU) are described in the text. 

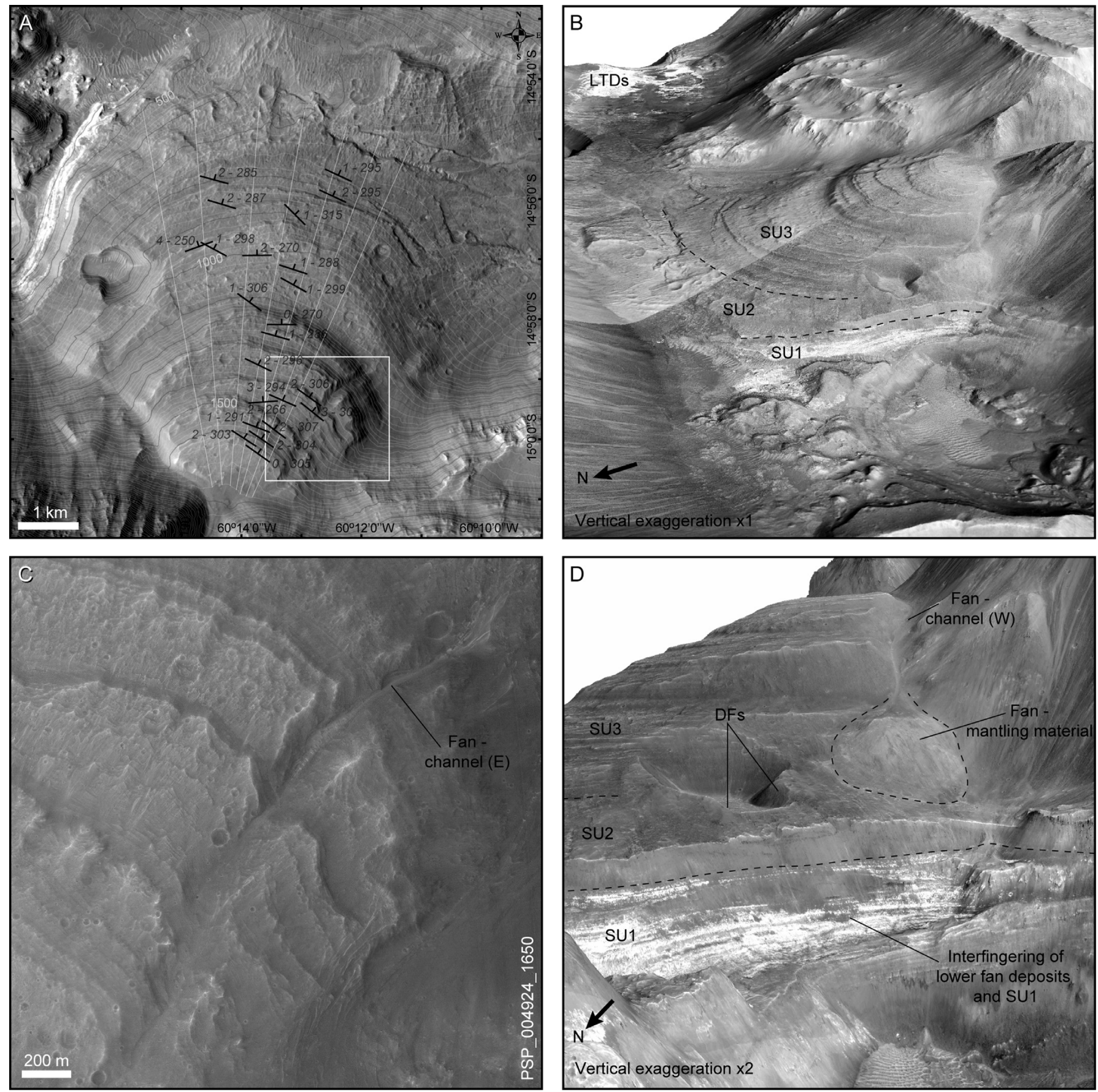

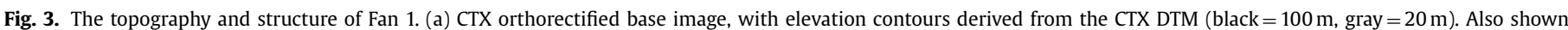

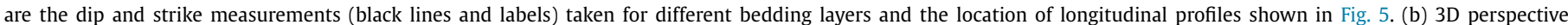

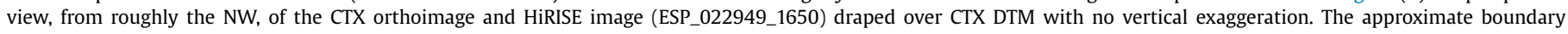

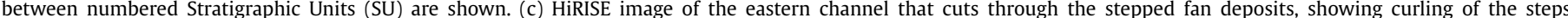

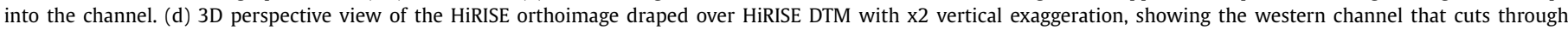
stepped fan deposits, the location of possible delta foresetts (DF), and also interfingering of lower fan deposits and SU1.

the scarps pinch off laterally, which suggests that if the flat-lying terraces represent the contact planes of distinct sedimentary packages, then at least some must have a lobate form. Where measurable, these step surfaces are observed to dip gently $\left(1.7^{\circ} \pm 0.9^{\circ}\right)$ away from the channel with a strike $\left(292^{\circ} \pm 16^{\circ}\right)$ aligned with that of the trough (Fig. 3a). We observe no change in dip or strike in the steps as a function of elevation. Using the planes fitted to the steps to derive the structural measurements, we estimate the height of these steps to vary between 4 and $166 \mathrm{~m}$, with a mean and standard deviation of $40 \pm 28 \mathrm{~m}$ (Table 2). The widest step, which is in the mid-part of the fan succession, has a height of only $68 \mathrm{~m}$, with the highest step occurring in the proximal deposits. The fan contains two small channels, one in the east and one in the west. Beginning near the top of the highest stepped layer, we observe a $\sim 300 \mathrm{~m}$ wide channel-like feature in the east of the fan that has incised to a depth of $\sim 10-20 \mathrm{~m}$ throughout the upper half of the fan layers. Material that mantles some of the fan surface, obscuring the eastern distal fan deposits, is likely sourced from this eastern channel. Within this eroded channel we observe that the stepped fan morphology curls upstream into the canyon, 
Table 2

Measurements of structural planes at each fan region.

\begin{tabular}{|c|c|c|c|c|c|c|c|}
\hline Number of points & $\operatorname{Dip}\left({ }^{\circ}\right)$ & Strike $\left(^{\circ}\right)$ & Correlation coefficient & Goodness of fit (\%) & Trace length (m) & Elevation range $(\mathrm{m})$ & Mean elevation (m) \\
\hline \multicolumn{8}{|l|}{ Fan $1-C T X$} \\
\hline 27 & $1 \pm 0$ & $295 \pm 5$ & 0.99748 & 99.50 & 3644 & 14 & 757 \\
\hline 16 & $2 \pm 1$ & $285 \pm 19$ & 0.99828 & 99.66 & 1957 & 31 & 806 \\
\hline 30 & $2 \pm 0$ & $295 \pm 6$ & 0.99584 & 99.17 & 3220 & 22 & 810 \\
\hline 17 & $2 \pm 1$ & $287 \pm 8$ & 0.99967 & 99.93 & 2385 & 55 & 864 \\
\hline 29 & $1 \pm 0$ & $315 \pm 14$ & 0.99857 & 99.71 & 3557 & 47 & 895 \\
\hline 17 & $4 \pm 1$ & $250 \pm 12$ & 0.99373 & 98.75 & 1193 & 13 & 950 \\
\hline 14 & $1 \pm 1$ & $298 \pm 29$ & 0.99925 & 99.85 & 1273 & 15 & 973 \\
\hline 16 & $2 \pm 0$ & $270 \pm 3$ & 0.99893 & 99.79 & 2000 & 17 & 1001 \\
\hline 18 & $1 \pm 0$ & $288 \pm 8$ & 0.99657 & 99.32 & 2296 & 17 & 1036 \\
\hline 17 & $1 \pm 0$ & $299 \pm 17$ & 0.99543 & 99.09 & 2070 & 13 & 1054 \\
\hline 15 & $1 \pm 1$ & $306 \pm 44$ & 0.9954 & 99.08 & 1096 & 9 & 1122 \\
\hline 19 & $0 \pm 1$ & $270 \pm 29$ & 0.97801 & 95.65 & 1649 & 4 & 1205 \\
\hline 16 & $1 \pm 0$ & $286 \pm 11$ & 0.98084 & 96.20 & 1471 & 2 & 1245 \\
\hline 30 & $2 \pm 0$ & $296 \pm 7$ & 0.99598 & 99.20 & 3018 & 44 & 1361 \\
\hline 18 & $2 \pm 1$ & $306 \pm 14$ & 0.99479 & 98.96 & 1444 & 11 & 1394 \\
\hline 21 & $3 \pm 0$ & $309 \pm 07$ & 0.99881 & 99.76 & 1416 & 16 & 1411 \\
\hline 20 & $3 \pm 1$ & $294 \pm 16$ & 0.99455 & 98.91 & 2009 & 30 & 1426 \\
\hline 27 & $2 \pm 1$ & $266 \pm 9$ & 0.99864 & 99.73 & 2389 & 52 & 1447 \\
\hline 19 & $2 \pm 1$ & $307 \pm 16$ & 0.99167 & 98.34 & 2532 & 31 & 1540 \\
\hline 18 & $1 \pm 1$ & $291 \pm 11$ & 0.9902 & 98.05 & 1969 & 17 & 1561 \\
\hline 24 & $2 \pm 0$ & $304 \pm 11$ & 0.9946 & 98.92 & 2278 & 34 & 1590 \\
\hline 25 & $2 \pm 0$ & $303 \pm 13$ & 0.98841 & 97.70 & 1963 & 19 & 1617 \\
\hline 20 & $0 \pm 0$ & $305 \pm 20$ & 0.98463 & 96.95 & 2009 & 7 & 1637 \\
\hline \multicolumn{8}{|l|}{ Fan 2-HiRISE } \\
\hline 15 & $3 \pm 2$ & $83 \pm 28$ & 0.99848 & 99.70 & 294 & 12 & -19 \\
\hline 17 & $5 \pm 3$ & $86 \pm 11$ & 0.99727 & 99.45 & 224 & 6 & 38 \\
\hline 17 & $5 \pm 2$ & $92 \pm 5$ & 0.9997 & 99.94 & 304 & 9 & 56 \\
\hline 17 & $6 \pm 3$ & $89 \pm 12$ & 0.99737 & 99.48 & 800 & 28 & 69 \\
\hline 17 & $7 \pm 3$ & $90 \pm 12$ & 0.9983 & 99.66 & 337 & 14 & 76 \\
\hline 26 & $10 \pm 3$ & $74 \pm 7$ & 0.99485 & 98.97 & 922 & 24 & 84 \\
\hline 23 & $3 \pm 1$ & $98 \pm 11$ & 0.99976 & 99.95 & 393 & 10 & 86 \\
\hline 24 & $7 \pm 3$ & $86 \pm 19$ & 0.99914 & 99.83 & 325 & 21 & 91 \\
\hline 25 & $7 \pm 4$ & $92 \pm 20$ & 0.99754 & 99.51 & 218 & 14 & 94 \\
\hline 25 & $3 \pm 1$ & $100 \pm 13$ & 0.99847 & 99.69 & 308 & 12 & 103 \\
\hline
\end{tabular}

suggesting that the steps were etched into the fan after channel downcutting (Fig. 3c). In the west of the fan, we observe a channel that is more subtle due to dust masking major albedo differences, but which is up to $500 \mathrm{~m}$ in width and $50 \mathrm{~m}$ in depth. We again observe the fan steps curling into the channel. At the end of this small channel lies a fan deposit that is $\sim 1 \times 1 \mathrm{~km}$ in width and length and up to $50 \mathrm{~m}$ in thickness and mantles the stepped deposits (Fig. 3d). On the trough floor, the contact between the edge of Fan 1 is often indistinguishable from mantling material. Only at the western edge of the fan are the lowest stratigraphic layers in the system revealed. Here, we observe layered LTDs (Fig. 3b) that are stratigraphically beneath the primary fan deposits and in places interfinger with the lowermost fan horizons (Fig. 3d). The LTDs have a similar appearance at HiRISE resolution to LTDs on the trough floor approximately $500 \mathrm{~m}$ to the northwest of the fan LTDs, and also to the LTDs in the east of the same trough studied in detail by Grindrod et al. (2012).

Fan 2 exhibits a well-defined stepped appearance only in the most proximal upper half of the fan succession (Fig. 4), with between 20 and 25 steps that are identifiable at HiRISE resolution. Besides the fan top surface, the broadest step level is approximately $250 \mathrm{~m}$ wide, with the smallest step being of the order of $1 \mathrm{~m}$ in width. It is not possible to trace each step layer across the entire fan arc of $\sim 140^{\circ}$. As on fan 1 , the scarps often decrease in height until pinching out laterally, possibly suggesting a lobate structure in the deposits at this scale. However, those steps that are sufficiently well-defined are observed to dip $\left(5.6^{\circ} \pm 2.3^{\circ}\right)$ away from the channel with a strike $\left(89^{\circ} \pm 7^{\circ}\right)$ aligned with that of the trough (Fig. 4c and Table 2). Again, we see no significant change in dip and strike in the steps as a function of elevation (Fig. 5). Small channels, $\sim 10 \mathrm{~m}$ in width and $2 \mathrm{~m}$ in depth, are seen to cut into at least two step surfaces, although the channels are disrupted by the step risers, suggesting that the steps formed after channel formation (Fig. 2b). Stratigraphically-below the stepped unit, distal fan deposits comprise a unit that shows a surface morphology characterized by a ridged, digitate appearance. The ridges comprise more resistant units interstratified in recessively weathering massive strata. The ridges, which occasionally crosscut each other, extend radially down the deposit, often reaching distances similar to the entire length of the stepped deposits $(\sim 1.5 \mathrm{~km})$, and in some cases to the base of the LTDs on the opposite side of the trough (distance of $\sim 3 \mathrm{~km}$ ). Individual ridges are typically $\sim 150 \mathrm{~m}$ long, though individual examples may extend $>500 \mathrm{~m}$ down the deposit. This stratal unit is characterized by a steeper present-day surface gradient (Fig. 6).

LTDs predominantly outcrop along an $\sim 8.5 \mathrm{~km}$ long cliff-like face to the south of the trough, opposite Fan 2, but not in the trough walls themselves. The height and slope of these deposits are typically $260-280 \mathrm{~m}$ and $20-40^{\circ}$ respectively. The lower edge of the top surface of the large LTD outcrop has a similar height (elevation $\sim 0 \mathrm{~m}$ ) to the contact between the higher stepped deposits and lower digitate deposits in the fan. The LTDs are capped with a dark, uniform mantling unit and the top surface dips moderately into the trough. No obvious layers are present in the bulk of the large LTD outcrop, rather the surface has a mottled appearance that becomes more polygonized toward the base of the outcrop (Fig. 4f). Faint, but laterally extensive layers are however visible at the very top of the stack. Smaller, isolated outcrops of LTDs that are similar in texture to the large outcrop also occur at the edge of the fan deposits at the base of the observable sequence, sometimes up to $100 \mathrm{~m}$ in thickness, particularly at the western margin of the fan deposits. We observe LTDs interfingering with the ridged deposits throughout the lower portions of Fan 2 (Fig. 4e). 

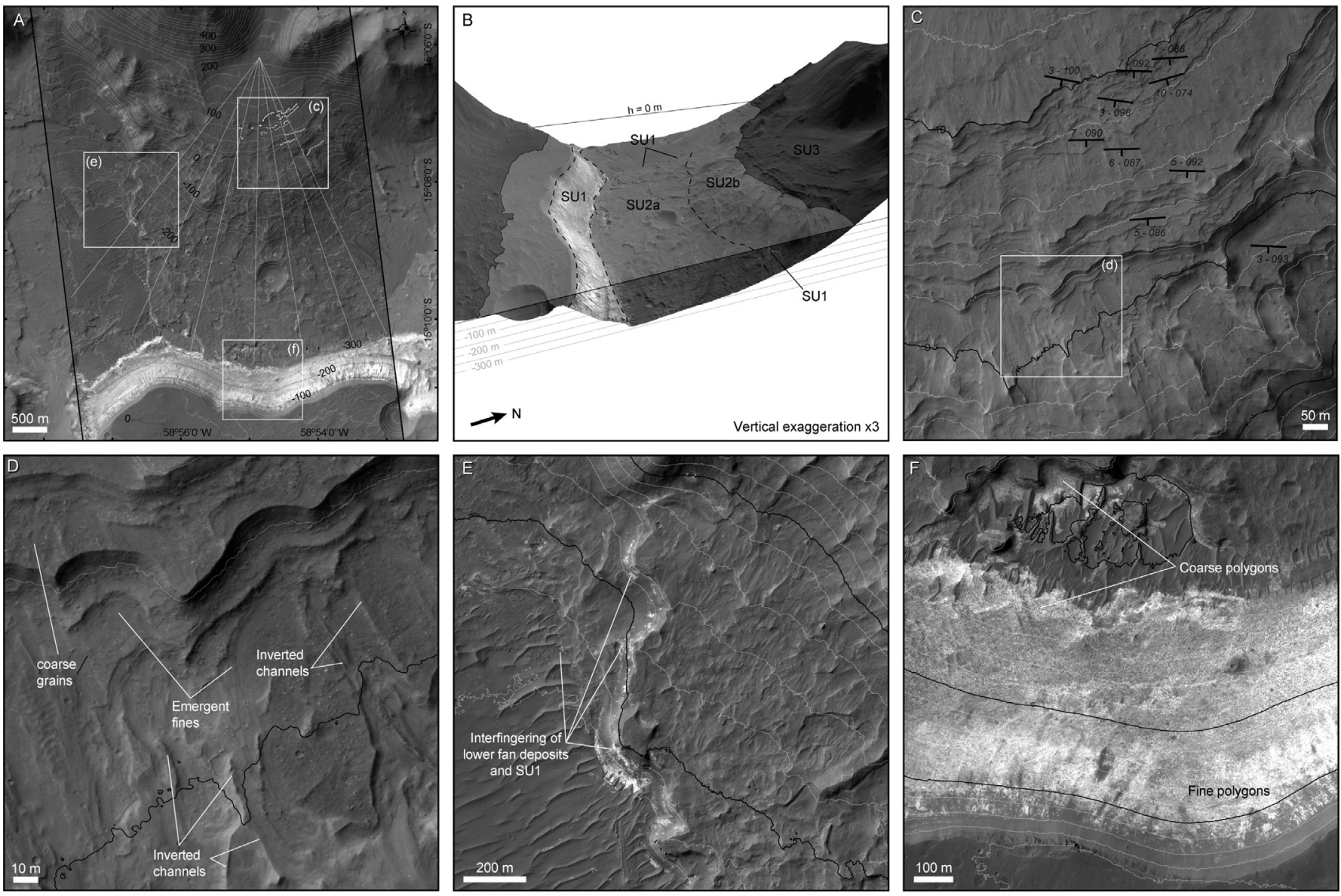

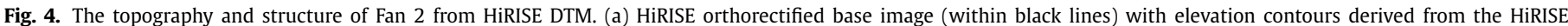

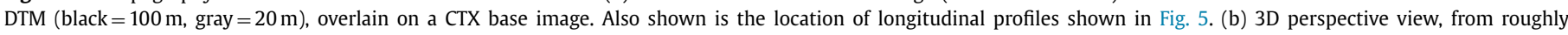

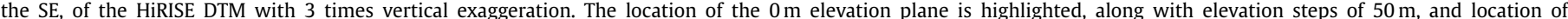

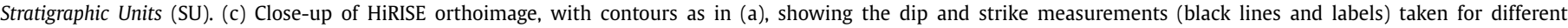

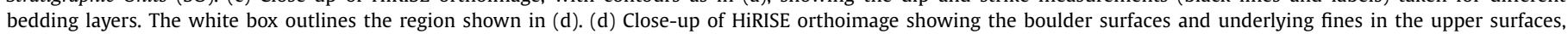

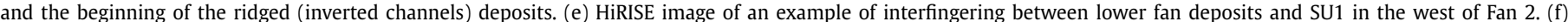
HiRISE image of the LTDs, showing possible coarsening up sequence.

Fan 1 is larger in size than Fan 2, with a length and height of 6.3 and $1.0 \mathrm{~km}$ respectively, compared to Fan 2 that has a length and height of 4.4 and $0.5 \mathrm{~km}$ respectively (Fig. 6). This size difference is therefore reflected in the overall area of each fan, with Fan 1 and Fan 2 having surface areas of 39.1 and $12.6 \mathrm{~km}^{2}$ respectively. Using a similar method to Lucas et al. (2011) of manually removing the fan from the elevation datasets to derive a pre-fan surface, we estimate the volume of Fan 1 and 2 at 6.1 and $0.8 \mathrm{~km}^{3}$ respectively. The two fan systems have similar minimum and maximum slope values but show a different surface slope profile as a function of distance. The slope of Fan 1 is less than $5^{\circ}$ on top of the most proximal deposits, before increasing to $15-20^{\circ}$ at intervals corresponding to the individual stepped layers. The slope values return to $<10^{\circ}$ at about $3.1 \mathrm{~km}$ distance until the end of the fan, corresponding to the distal fan deposits. The slope profile of Fan 2 differs to that of Fan 1, with a consistent value of between 5 and $10^{\circ}$ on the stepped surfaces gradually increasing to $\sim 15-20^{\circ}$ at the transition to the digitate units, before decreasing back to initial values by the end.

\subsection{Fan sedimentology and stratigraphy}

Unlike many fan or delta systems on Mars (e.g., Kraal et al., 2008; Hauber et al., 2009) these fans are unusual in that some aspects of their process stratigraphy can be interpreted from
HiRISE-scale imagery. We are able to use exposed dip parallel structures in the fans (exposed resistant beds, lenticular channelform beds) to quantitatively constrain their stratigraphy. In this section we describe sedimentary units common at both fan systems: Stratigraphic Unit 1-light-toned deposits; Stratigraphic Unit 2-Ribbon-channel deposits; Stratigraphic Unit 3-sheet-like deposits.

\subsubsection{Fan 1}

A unique feature of Fan 1 is that erosion and collapse have exposed partial cross-sections of the stratigraphy in two locations in the lowest step of the fan. Stratigraphic Unit 1 is the lowest unit within the fan, made up of LTDs, which interfinger with the unit directly above. Stratigraphic Unit 2 is composed of ridged material, where occasionally, and especially on the lowest parts of the fan, indistinct channel-like ridges can be seen emerging from the base of riser faces and traversing the step below (as also noted by Di Achille et al., 2006). Here, we are able to see possible horizontal bed rollover into foresets within the sediment package (Fig. 3b). All beds higher up the fan appear to be sub-parallel with no further signs of foresets. Stratigraphic Unit 3 is a sheet-like unit, composed of flat benches capped with possible coarse-grained material. The faces of the scarps are poorly exposed in part due to lower step height, but we infer that the step faces are finer grained than the caps (see Fan 2 description). 
A

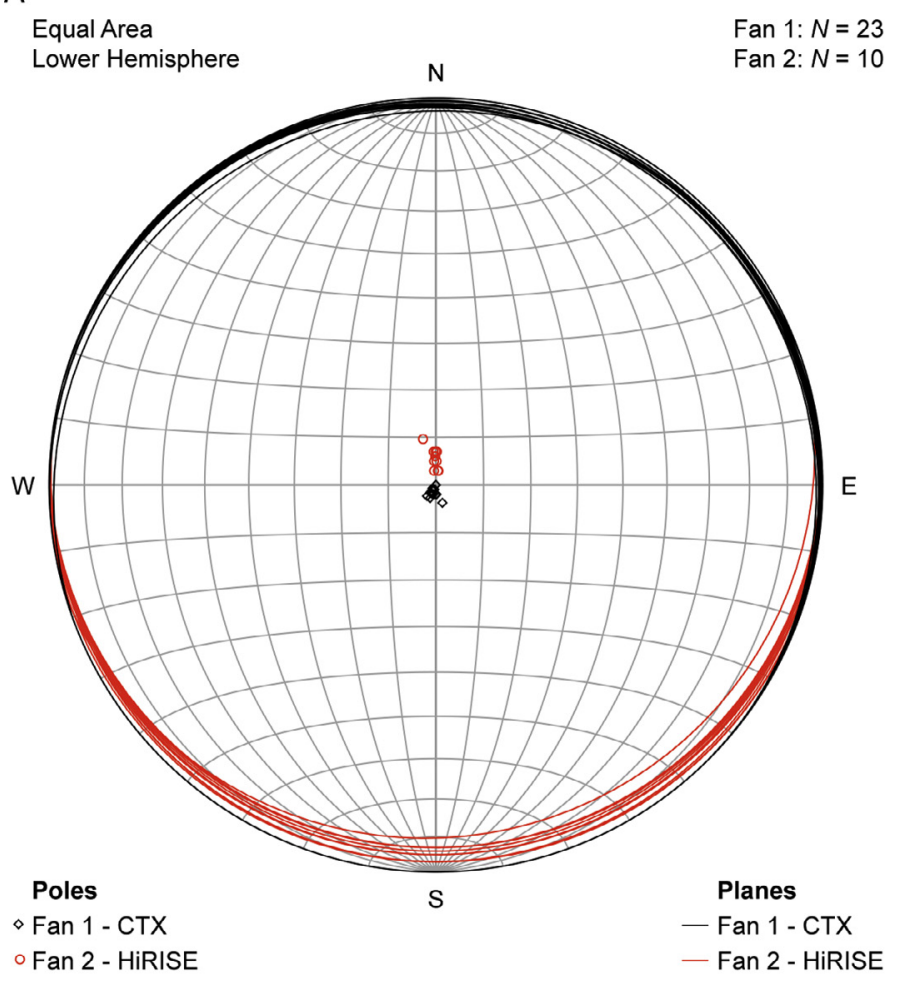

B Fan 1- CTX
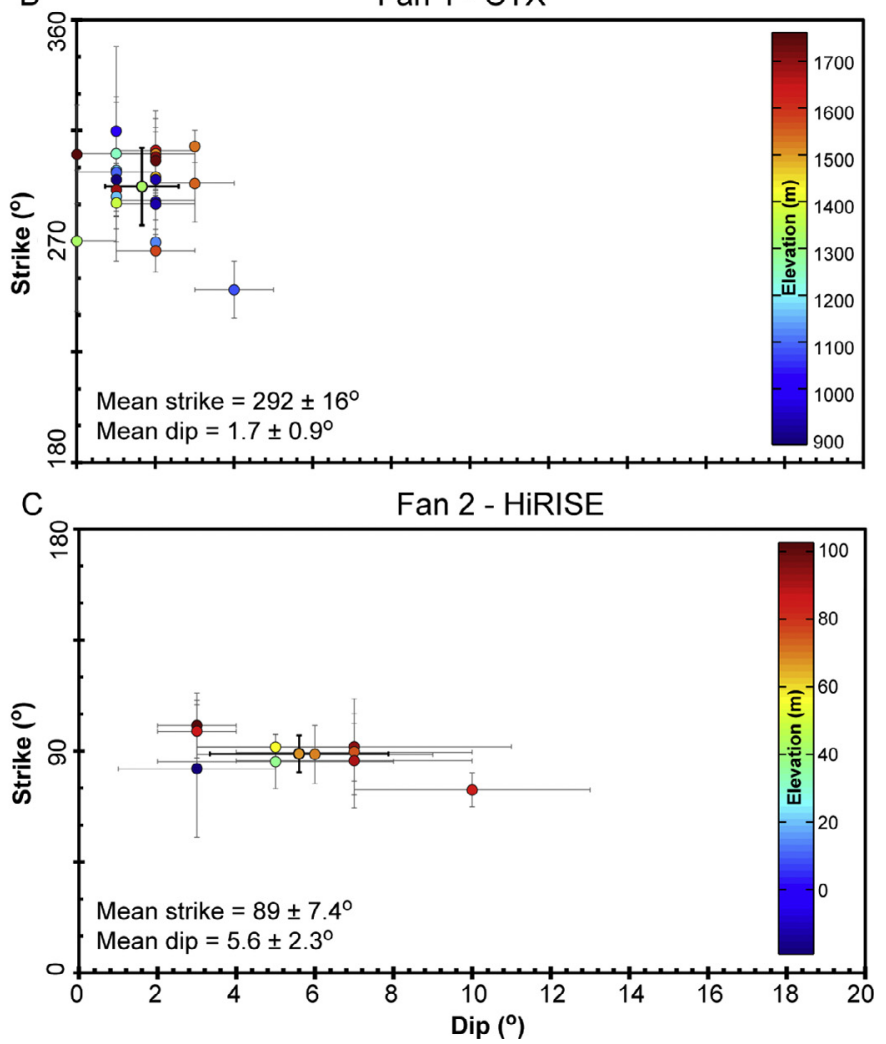

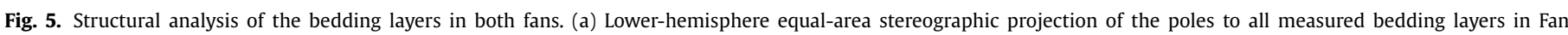

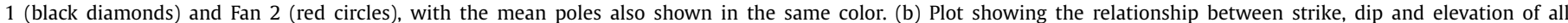

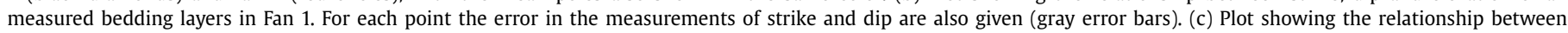

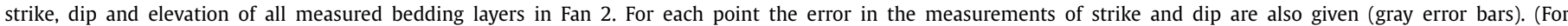
interpretation of the references to colour in this figure legend, the reader is referred to the web version of this article.)

\subsubsection{Fan 2}

With our HiRISE DTM at Fan 2, we can compare the stratigraphic dips of the individual beds to those of the ridged deposits, estimated by fitting lines of dip to elevation points extracted from individual ridge traces. The dips extracted from the bedding (Fig. $4 \mathrm{c}$ and Table 2 ) and from the ridges $\left(\sim 5-10^{\circ}\right)$ are entirely consistent, and confirm that the fan has three distinct facies divisions: Stratigraphic Unit 1-occurs as (1) small outcrops of light-toned deposits at the base of the fan deposits, particularly in the west of the fan, and (2) large-scale LTDs that are opposite the fan, both of which are interstratified with overlying ridged facies; Stratigraphic Unit 2-ridged deposits that can be split into two subfacies (a) ridged distal facies where slopes gradually decrease to $\sim 0^{\circ}$ away from the fan apex, and associated with finer-grained radial ridges, (b) ridged proximal facies with steeper slopes, up to $\sim 18^{\circ}$, with the top of this unit corresponding to the onset of the ridged facies; Stratigraphic Unit 3-a top unit of constant dip down fan of $\sim 6^{\circ}$, which corresponds to the alternating deposits of coarse sheets and underlying finer material, into which steps develop.

At maximum resolution at HiRISE scales, the surfaces of individual steps in the upper stratigraphy of Fan 2 reveal a possible coarser grain size than the lower part of the steps (Fig. 4d). The coarse material in Stratigraphic Unit 3 is up to several pixels in width, with a maximum diameter of $\sim 1.5 \mathrm{~m}$. All sizes below $1.5 \mathrm{~m}$ and to the resolvable limit of rocks in HiRISE ( 4 pixels, $\sim 1 \mathrm{~m}$ ) are also visible. Where these surfaces come to the edge of a scarp, it is apparent that this is not only a surface lag texture, but that boulders and the speckled texture are also present throughout the top bedded unit (Fig. 4c). However, beneath this capping bed, the bulk of each scarp face is composed of sediments in which there is no apparent grain scale texture, and which we interpret to be composed of sediments where the maximum grain size is below the resolution of the camera. Where coarser beds are again seen in the lower parts of scarps, they form the cap of a new, positive relief bench, which juts from the face. Thin veneers of the finer material are sometimes exposed on the tops of benches, where they develop a scalloped erosion surface.

The surfaces of the digitate ridges in Stratigraphic Unit 2 are likewise composed of this coarse-grained material. However, the ridges are set among beds of the finer lithology (Fig. 4c). Coarsegrained sheets are not present in this part of the fan. This texture is reminiscent of that seen in Saheki crater (Morgan et al., 2014) and as channels with inverted topography eroding out of finergrained overbank deposits. The maximum observable grain size in the ridges appears to decrease down fan, until indistinguishable from the surrounding fines in the most distal ridges. Individual ridges from different stratigraphic layers are all exposed at the surface, leading to an apparently higher density of ridges, and also exposing some ridge crosscutting.

\subsection{Orbital mineralogy}

We use both full- and half-resolution CRISM observations to gather detailed information of the mineralogy of the fans and associated light-toned deposits, which are limited to the Fan 2 region. Despite one of the CRISM images not being full resolution, the data are still sufficient to identify a distinctive hydrous mineralogy associated with the LTDs in the base of the trough and their relationship to Fan 2 . The overall dominant alteration spectral signature in this trough system is that of phyllosilicates, with 

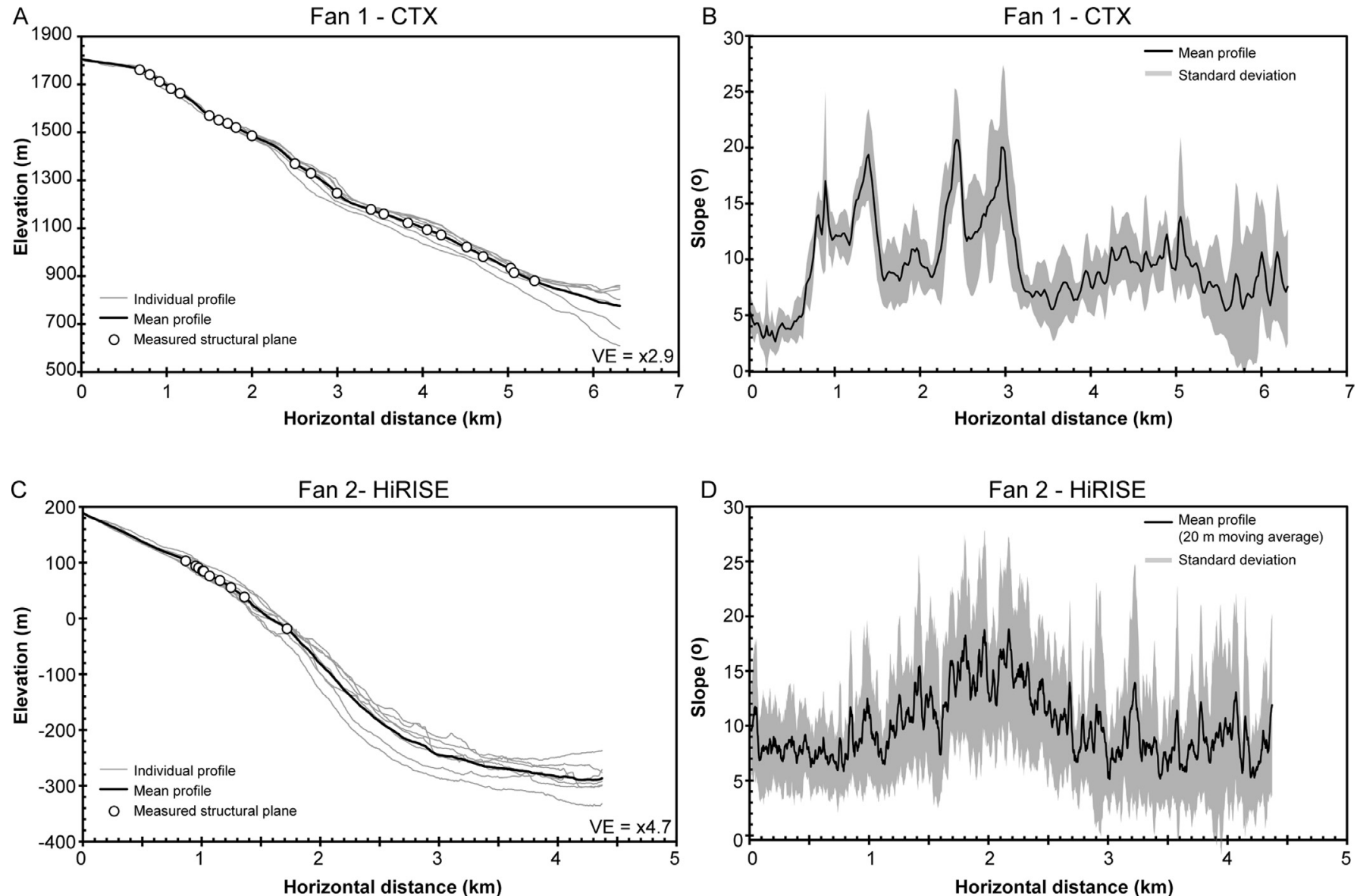

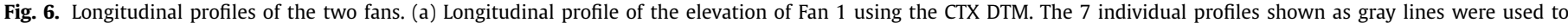

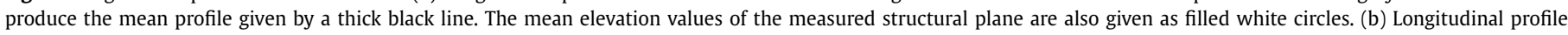

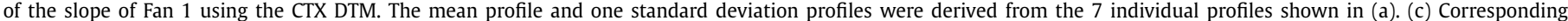

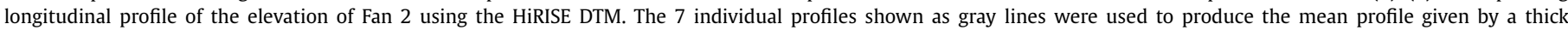

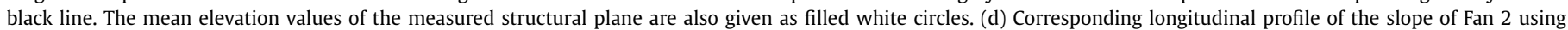

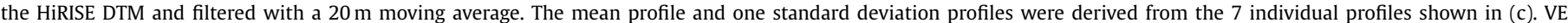
is the vertical exaggeration in each case.

distinctive absorption features at $2.3 \mu \mathrm{m}$, and some smaller areas having absorption features around $2.2 \mu \mathrm{m}$ (Figs. 7 and 8). Spectral parameter summary images highlight the distribution of these absorption features. The strongest alteration signatures, centered around $2.3 \mu \mathrm{m}$, are confined to Stratigraphic Unit 1, LTDs exposed both in the bottom of the trough, opposite Fan 2, and in isolated outcrops in the walls at the top of the trough. The LTDs show strong absorption features at $2.3 \mu \mathrm{m}$, with sharp boundaries with surrounding mantling material (Fig. 7). The absorptions around $2.3 \mu \mathrm{m}$ are strong throughout the LTDs, with a possible transition toward stronger absorptions centered around $1.9 \mu \mathrm{m}$ toward the upper parts of the LTDs. Absorption features centered around $2.2 \mu \mathrm{m}$ occur predominantly in LTDs located on the plains outside the trough, and in one location appear to be outcropping directly above the $2.3 \mu \mathrm{m}$ material toward the top of the trough walls (Fig. 8).

Spectra taken from locations identified using the spectral parameter summary images highlight not only the dominant signature of phyllosilicates, but also two possible different major types of phyllosilicates (Fig. 9). Spectra taken at the locations LTD1 and LTD2 have dominant absorption features at 2.3 and $2.4 \mu \mathrm{m}$, and also around 1.4, and 1.93, suggesting a mineralogy similar to $\mathrm{Fe} / \mathrm{Mg}$ phyllosilicates such as saponite or nontronite. Similarly, the spectrum of material located at Wall LTD also shows absorption features typical of $\mathrm{Fe} / \mathrm{Mg}$ phyllosilicates. Whereas material found in the surrounding plains (Plains LTD) has a spectrum with an indicative broad absorption feature at $2.2 \mu \mathrm{m}$, with other absorptions at 1.4 and $1.9 \mu \mathrm{m}$, suggesting a mineralogy similar to Al phyllosilicates such as montmorillonite or kaolinite.

\subsection{Crater counting surveys}

We split our crater counting surveys into two distinct approaches: (1) a HiRISE-based study of all craters greater than $1 \mathrm{~m}$ in diameter, in attempt to determine any relative crater retention information about the fan systems, and (2) a CTX-based study to determine estimates of the absolute age of the plains surrounding the trough systems that contain both fans.

As in our previous study (Grindrod et al., 2012), our HiRISEbased approach is not intended to reveal absolute ages, but rather to provide the crater density of different surfaces through each of the fan systems. Notwithstanding the possible inherent problems in studies of small craters-see Grindrod et al. (2012) for discussion in this context-the main observation from our HiRISE-based study is that the upper surfaces of both Fan 1 (Fig. 10) and Fan 2 (Fig. 11) have a higher crater density than the lower surfaces. At Fan 1, crater densities reach a peak of about 0.007 craters per $50 \mathrm{~m}^{2}$ on the channel floor just before the fan unit begins (Fig. 12). The crater density then drops to approximately 0.002 craters per $50 \mathrm{~m}^{2}$ at the beginning of the proximal fan region, before 

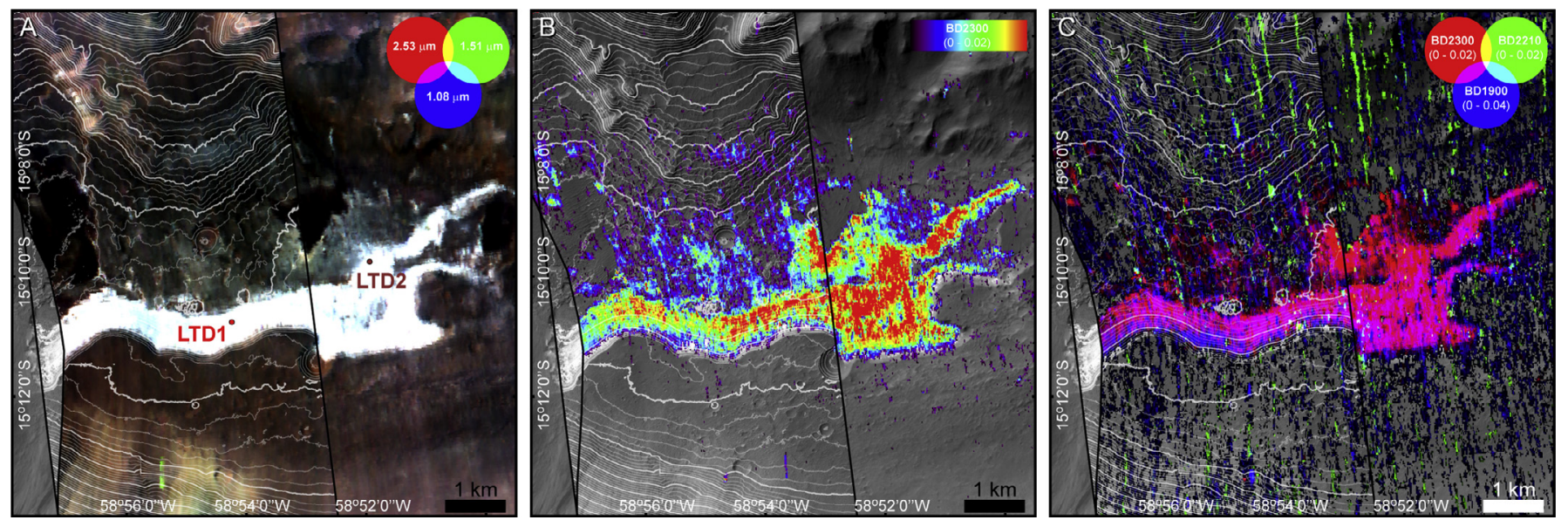

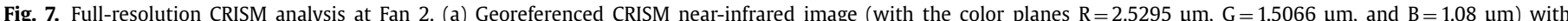

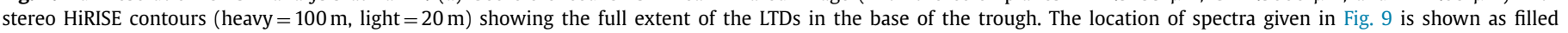

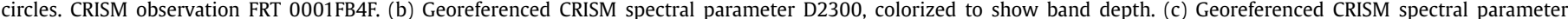

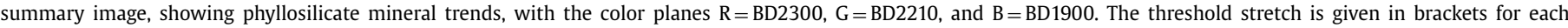

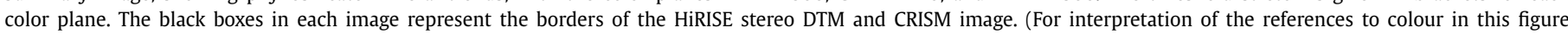
legend, the reader is referred to the web version of this article.)
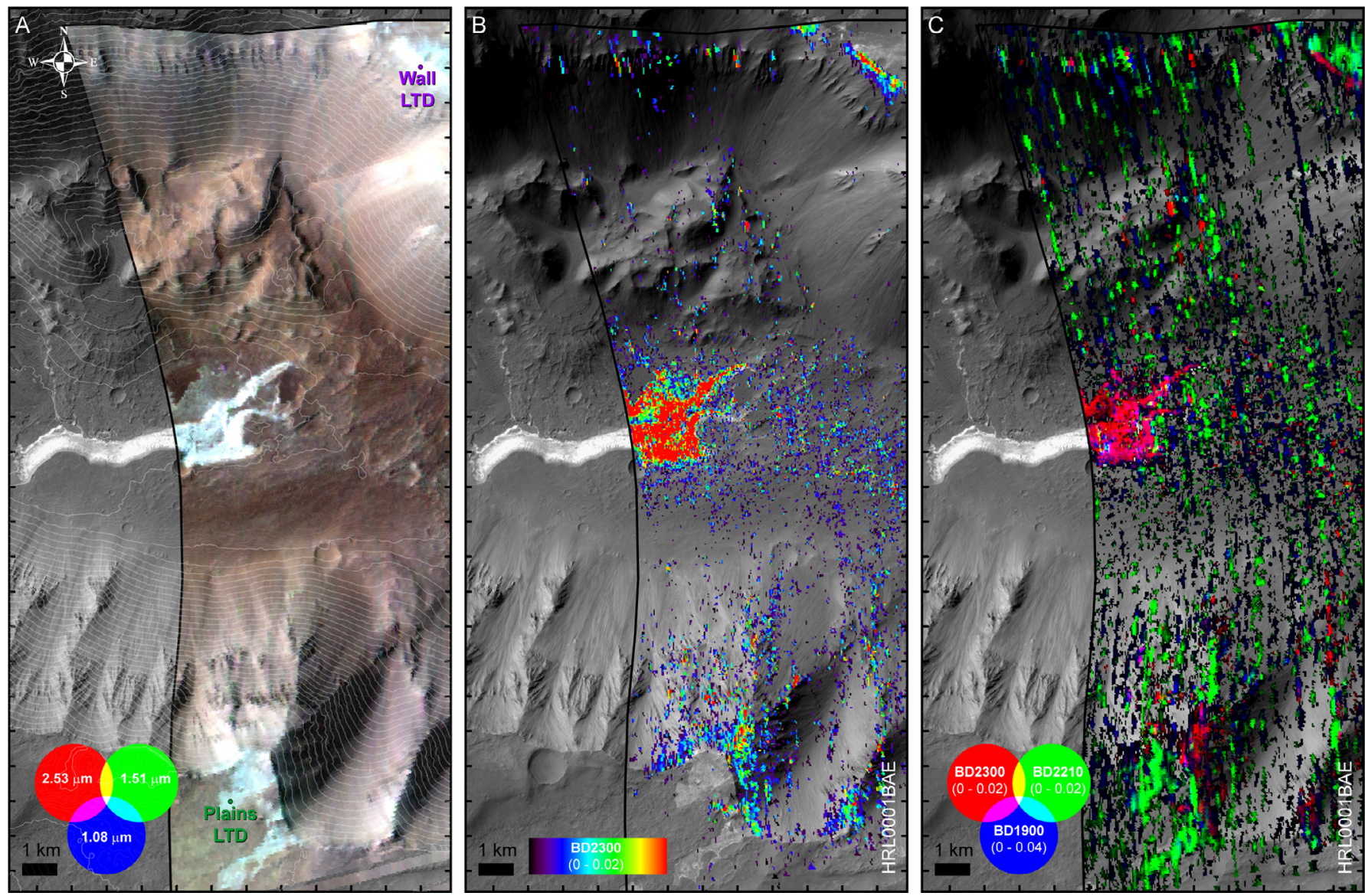

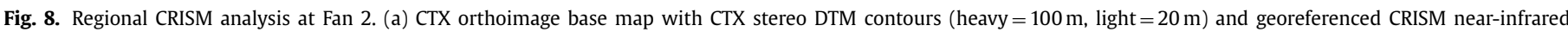

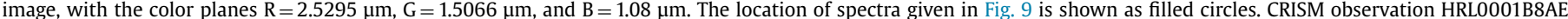

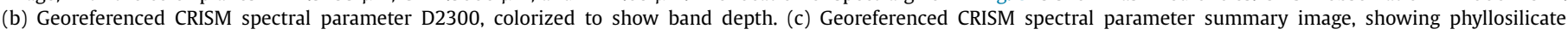

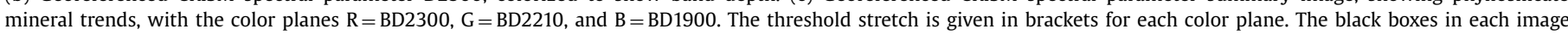

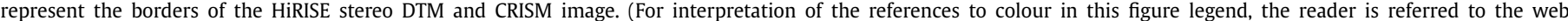
version of this article.) 


\section{A FRT0001FB4F}

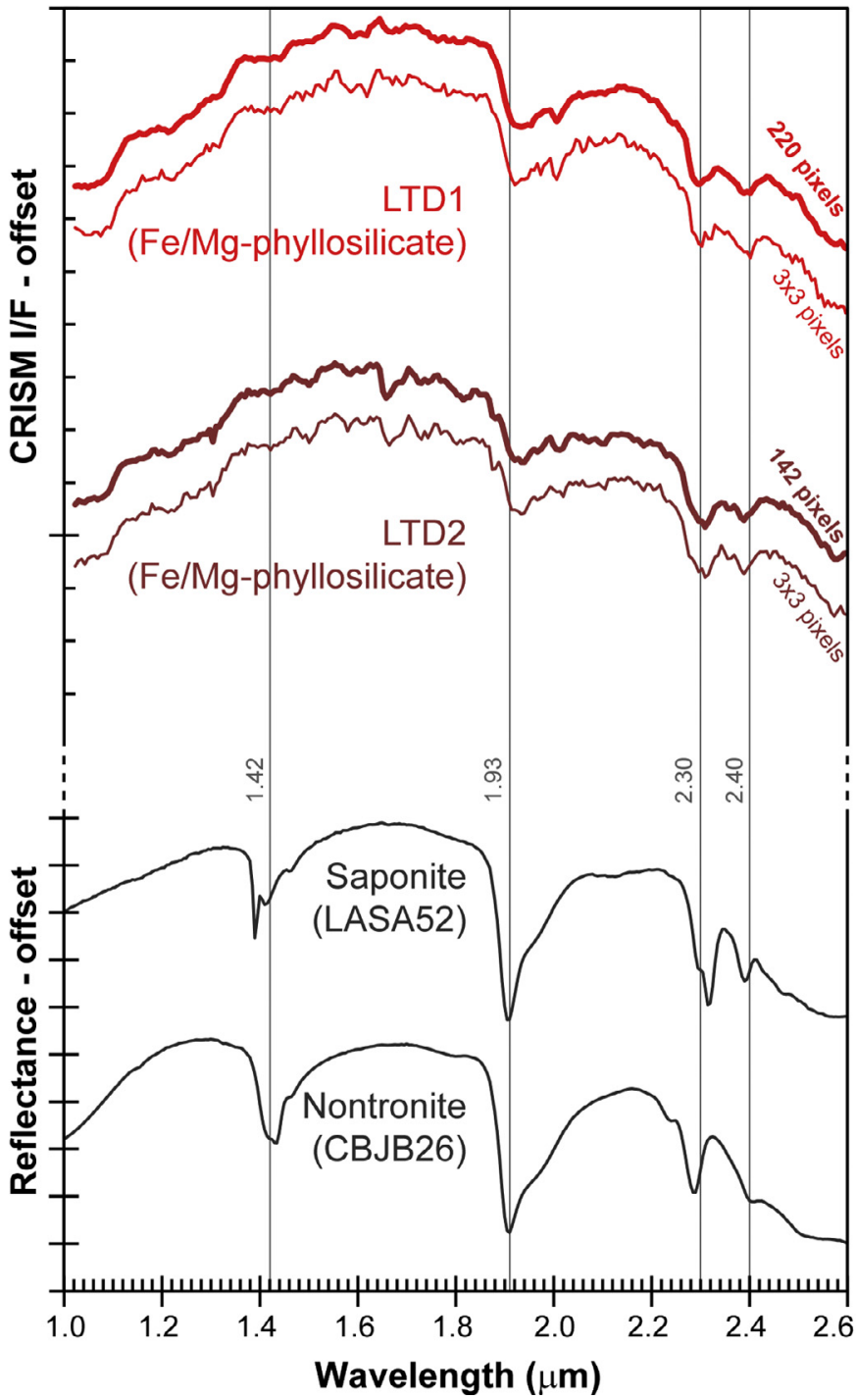

B HRL0001B8AE

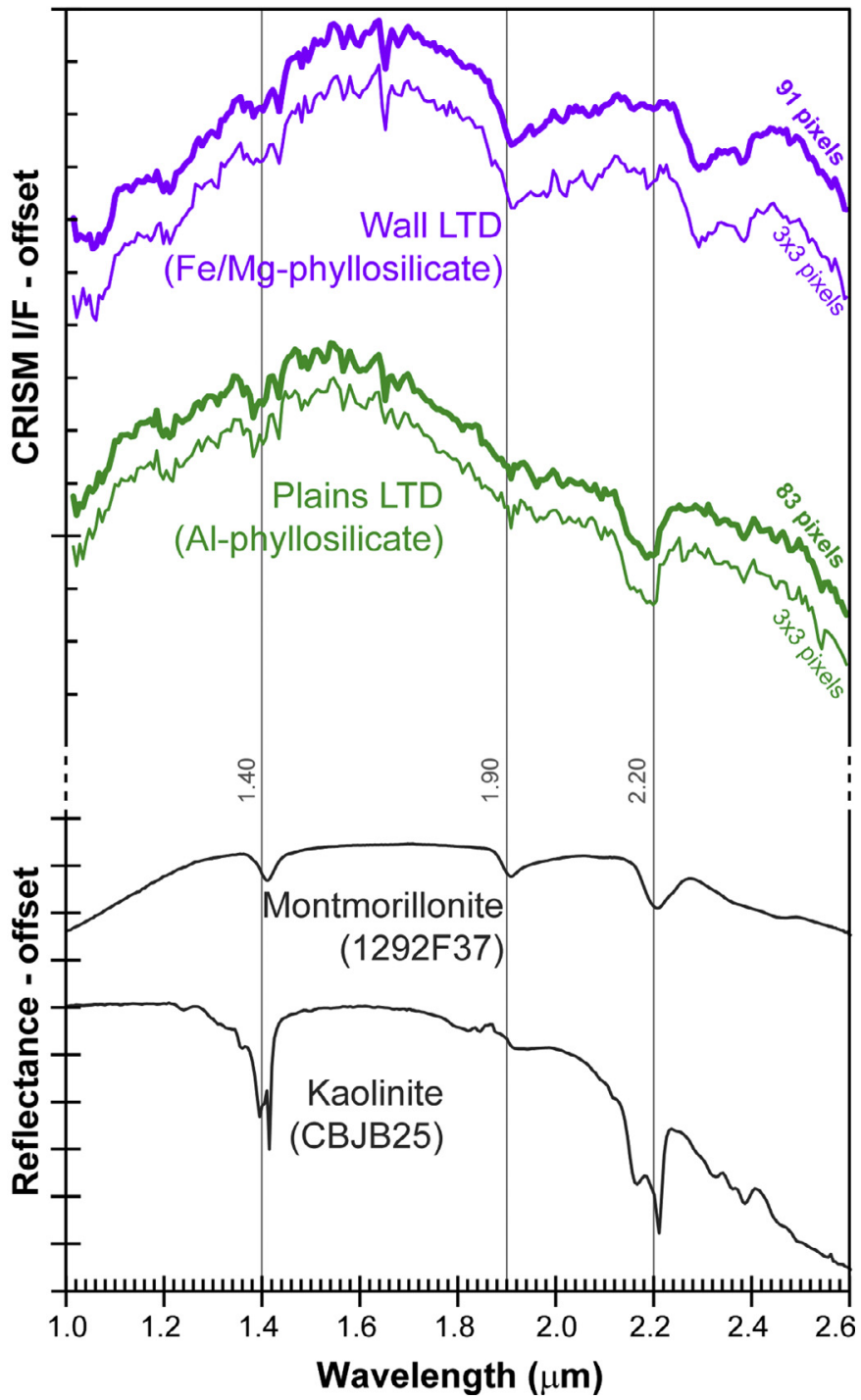

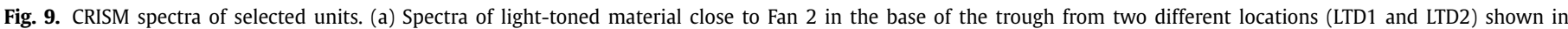

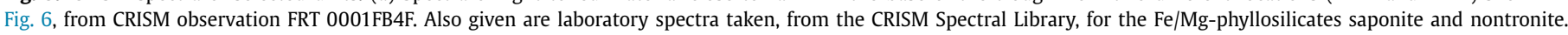

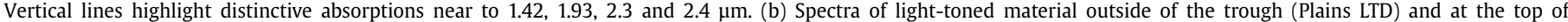

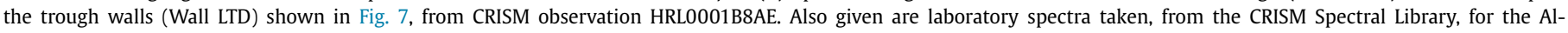

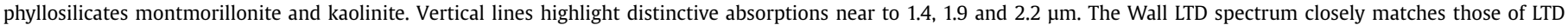
1 and 2 . In each case the thick line represents the spectrum from a region of interest, with number of pixels given, whereas a thin line represents a $3 \times 3$ pixel average.

increasing again to 0.005 craters per $50 \mathrm{~m}^{2}$ toward the middle of this unit. The crater density then drops again and, allowing for local variations along the profile chosen, remains between approximately 0.001 and 0.002 craters per $50 \mathrm{~m}^{2}$ before reducing to near to zero in the small area of LTDs and mantling material. Despite being smaller in overall size, Fan 2 shows a similar profile of crater density. An initial peak of almost 0.006 craters per $50 \mathrm{~m}^{2}$ occurs at the end of the channel floor before a drop and subsequent rise to almost 0.007 craters per $50 \mathrm{~m}^{2}$ on the proximal fan material. Low crater densities of about 0.001 craters per $50 \mathrm{~m}^{2}$ occur on the distal fan material before increasing again on the large area of LTDs and mantling material, reaching the overall maximum for this area at almost 0.009 craters per $50 \mathrm{~m}^{2}$. The trough walls in the Fan 2 region have crater densities lower than those found on the proximal fan material, but higher than those on the distal fan material.

To estimate the absolute age of different surfaces we used CTX images and standard crater counting techniques (Michael and Neukum, 2010), as in our previous studies (e.g. Grindrod and
Fawcett, 2011; Grindrod et al., 2012; Warner et al., 2010a, 2010b, 2010c). We split the absolute age dating into two main tasks: (1) general large cratered plains area, and (2) targeted small plains areas (Fig. 13), with all results given in Table 3. We first counted 6242 craters with diameters greater than $200 \mathrm{~m}$ in a cratered plains region to the south-west of our study regions, with an area of $\sim 26,000 \mathrm{~km}^{2}$. We derived a model age of $3.71 \mathrm{Ga}$ by fitting to 1362 craters between 0.5 and $20 \mathrm{~km}$ in diameter. We then counted all craters with diameters greater than $50 \mathrm{~m}$ in four smaller plains areas that surround the study troughs, but which all most likely represent similar geological units on a regional scale: two areas in the cratered plains and two areas in the inter-trough plains. In total we counted over 17,000 craters in an area of about $4000 \mathrm{~km}^{2}$, but limited our model age fits in each area to those given in Table 3. In each case we derived a model age from crater diameters that follow the established production functions. We interpret these ages to be the closest representation of the bulk surface age in an area. At diameters below 

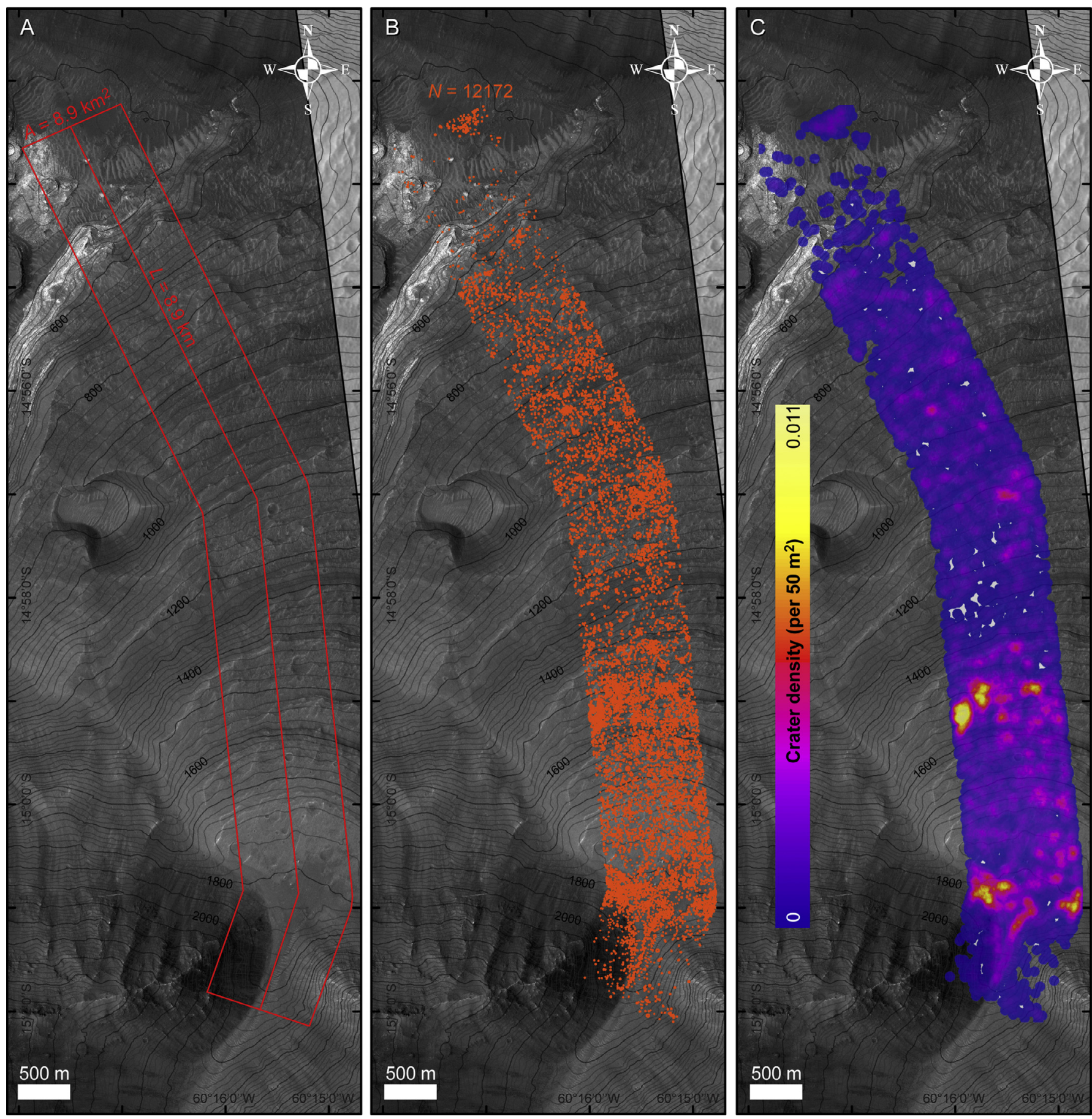

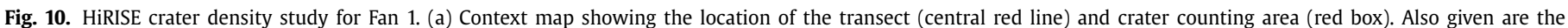

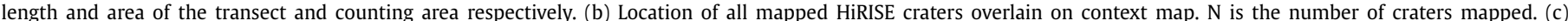

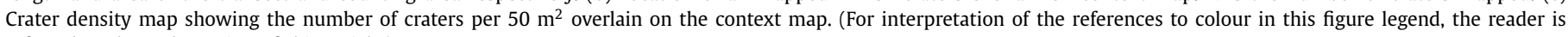
referred to the web version of this article.)

$300-500 \mathrm{~m}$ the slope of the crater size frequency distribution on all of the subset areas falls below the production functions. The steady decline in slope suggests a more steady-state erosive process that preferentially removes the smaller craters relative to the larger ones (e.g. Hartmann and Neukum, 2001; Hartmann, 2005; Michael and Neukum, 2010). From these data we make three primary observations: (1) overall the main surface of each representative plains unit ranges in age from Middle Noachian $(3.8 \mathrm{Ga})$ to Early Amazonian (2.63 Ga), (2) surfaces immediately surrounding the trough at Fan 1 are possibly younger than those surround- ing Fan 2, and (3) inter-trough surfaces are older than cratered plains surfaces. Regardless of location, most surfaces in this study have likely undergone some crater obliteration at small diameters (Fig. 13b-e).

\section{Discussion}

Our sedimentary geology and mineralogical observations enable us to develop a model for the depositional history of the sediment fan deposits (Fig. 11), with particular focus on (1) the relative and 

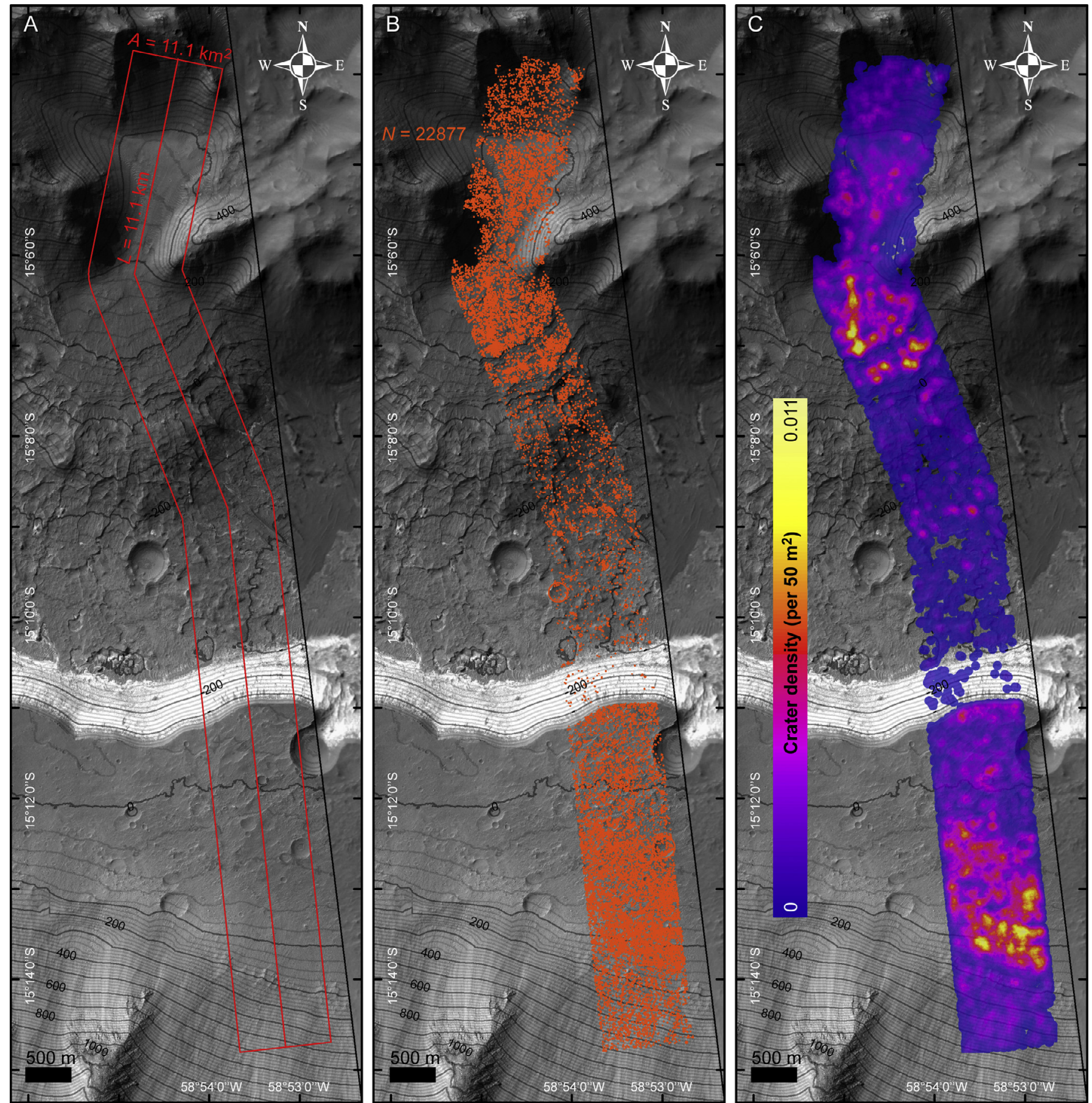

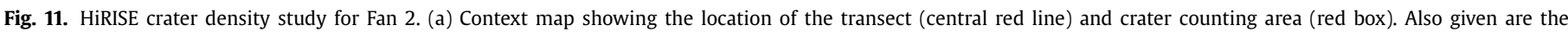

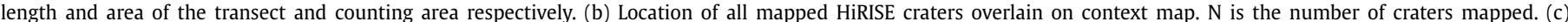

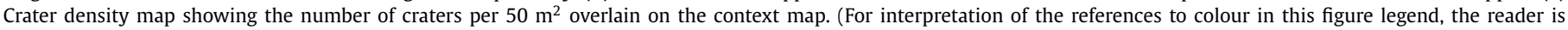
referred to the web version of this article.)

absolute timing of their formation, (2) the likely depositional and aqueous alteration environment, and (3) the implications for wider sedimentary and aqueous processes on Mars.

\subsection{Timing of trough formation, and fan and LTD deposition}

The overall preserved geomorphology of both fans suggests that they were deposited after their respective troughs they infill had formed. The absence of large-scale trough-related faulting or collapse within the fan stratigraphy suggests that signif- icant extension and/or subsidence, as predicted by the general Valles Marineris formation framework (e.g. Andrews-Hanna, 2012a, 2012b, 2012c), had largely ceased by the time of fan formation. However, at least one probable collapse feature is observed in the western part of Fan 1, indicating that at least some limited local subsidence or slumping did occur after the formation of the fans. The strike of the steps in the fans also matches well with the orientations of their respective troughs, supporting the hypothesis that they are the result of deposition in a low-lying trough, with little-to-no large-scale subsidence after formation. 


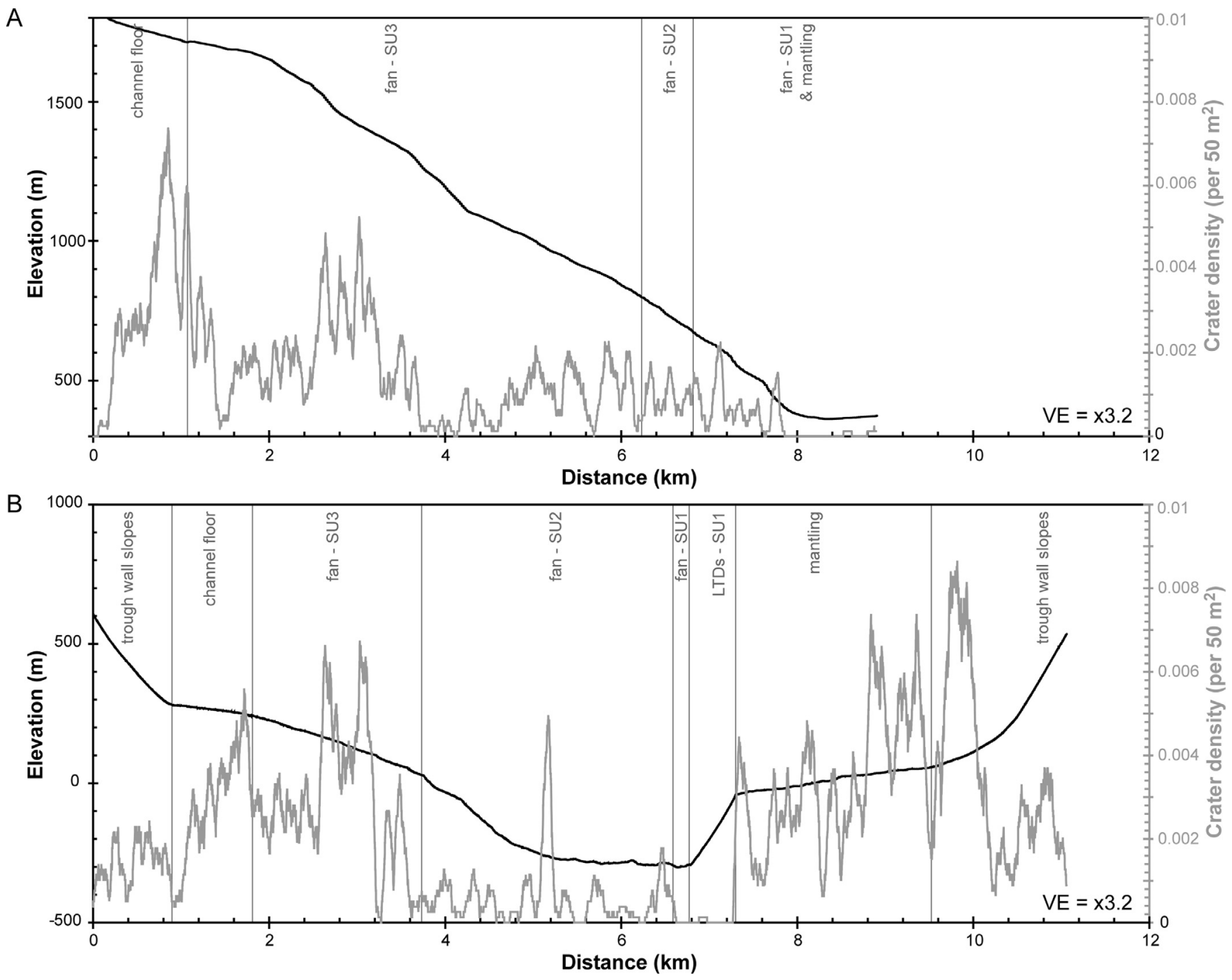

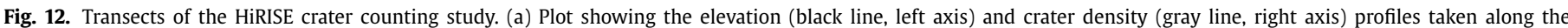

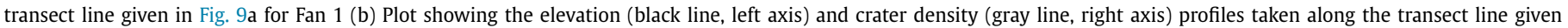
in Fig. 10a for Fan 2. In each case the locations of the different regions are labeled, and VE is the vertical exaggeration.

Table 3

Crater statistics for regions surrounding the troughs of the fan systems.

\begin{tabular}{|c|c|c|c|c|c|c|c|}
\hline Unit and surface & Area $\left(\mathrm{km}^{2}\right)$ & Craters & Fit range $(\mathrm{km})$ & $\mathrm{N}(1)$ & $\mathrm{N}(10)$ & Model age (Ga) & Stratigraphic age \\
\hline \multicolumn{8}{|l|}{ Large } \\
\hline Cratered plains & 26130 & 6242 & & & & & \\
\hline \multicolumn{8}{|l|}{ Fan 1} \\
\hline Cratered plains & 1154 & 8224 & & & & & \\
\hline Fit & & 94 & $0.30-1.30$ & $1.3 \times 10^{-3}$ & $1.8 \times 10^{-5}$ & $2.63+0.36 /-0.46$ & EA \\
\hline \multicolumn{8}{|l|}{ Fan 2} \\
\hline Cratered plains & 1432 & 5593 & & & & & \\
\hline Fit & & 26 & $0.60-1.20$ & $4.1 \times 10^{-3}$ & $5.9 \times 10^{-5}$ & $3.61+0.05 /-0.08$ & $\mathrm{EH}$ \\
\hline Inter-trough plains & 665.3 & 1178 & & & & & \\
\hline Fit & & 10 & $0.90-1.50$ & $1.0 \times 10^{-2}$ & $1.5 \times 10^{-4}$ & $3.8+0.06 /-0.10$ & LN \\
\hline
\end{tabular}

a Stratigraphic ages as defined in Hartmann and Neukum (2001).

However, there is evidence of either contemporaneous or postdepositional subsidence in some non-fan deposits, suggesting that these deposits pre-date the formation of the fans. The LTDs that are stratigraphically lowest in the Fan 1 succession, Stratigraphic Unit 1, have been affected by collapse both in the west of the trough and in the east (Grindrod et al., 2012). These collapse events have exposed the largest areas of LTDs visible in this trough, suggesting that further LTDs might be present under the dark mantling material but are only revealed through collapse and/or aeolian erosion. The lack of an obvious source channel for Fan 2 could at least in part be due to the slumping of large blocks from the northern walls of the trough. Although a distinctive channel is 

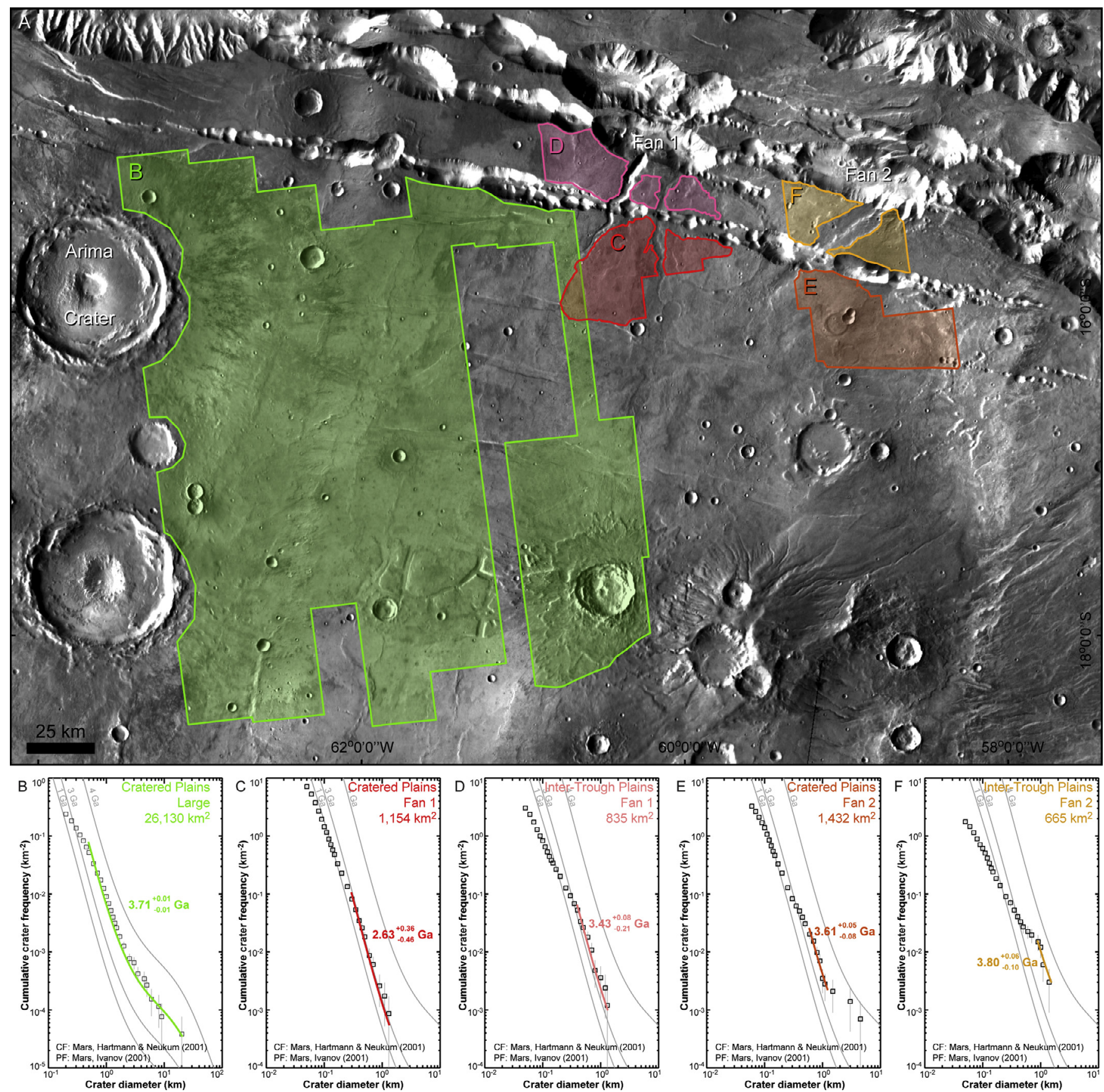

Fig. 13. Results of the CTX crater statistics study given in Table 1. (a) THEMIS context image showing the wider Coprates Catena Region with the location of the two study fans and crater counting areas. CTX images alone, not shown here, were used to count craters. Binned cumulative crater frequency histograms of (b) Large area cratered plains, (c) Fan 1-cratered plains, (d) Fan 1-inter-trough plains, (e) Fan 2-cratered plains, and (f) Fan 2-inter-trough plains. In each case the model fit to the surface is given in colors corresponding to crater counting regions in (a). (For interpretation of the references to colour in this figure legend, the reader is referred to the web version of this article.)

present at the apex of Fan 2, it is difficult to determine the previous channel path, suggesting that the slumping of these blocks has masked the original channel location. There is no evidence of collapse in Fan 2 or its associated LTDs and mantling material.

Given the inherent limitations of using crater density frequencies to derive an age estimate for features that are both small in size (e.g. Warner et al., 2015) and have a complicated burial and erosional history, we do not seek to derive a model age from our HiRISE crater study. Nonetheless, we can make several useful observations from the data that support our hypotheses. The upper surfaces of Stratigraphic Unit 3 and the mantling material of the LTDs at Fan 2 have similar crater densities, suggesting that the cessation of deposition for the fan and LTDs could be similar. However, the other surfaces within the trough and on the fan are notably more sparsely cratered. Since these surfaces are stratigraphically lower, and hence older that the more densely-cratered mantling units, this suggests that erosion on at least the scale of the depth of the bulk of the mapped craters has been important in the deposits in the region between the fan and LTDs, which has a lower crater density overall. This conclusion is further reinforced by the local densities of craters seen along the fan transect (Fig. 12), where both steeper and lower elevation surfaces are 
noticeably more crater-sparse that their lower gradient and higher equivalents. This pattern is consistent with the idea that steeper sloped surfaces are eroding and retreating back faster than their lower gradient neighbors (e.g. Penck, 1924). The LTD marginal cliff opposite Fan 2 for example has retreated all the way across the floor of the trough, only recently exposing the lowest elevations to crater impact. These observations imply that the current surface morphology of the fans, in particular the presence of distinctive steps, may largely be a function of later stage aeolian erosion and is not reflective of primary depositional processes.

Crater model ages from small area statistics on fans in general on Mars might not be reliable (see Warner et al., 2015 for discussion), as the uncertainties from such crater counts provide plausible model ages that in some cases span the entire geologic history of Mars. Therefore, because crater studies in our study troughs are too small and sparse to formally age date these surface, we step back to the larger plains outside of the troughs to derive absolute maximum ages for different surfaces. These plains have previously been interpreted as Noachian to Hesperian in age (e.g. Scott and Tanaka, 1986; Schultz, 1991; Witbeck et al., 1991; Anderson et al., 2001; Andrews-Hanna, 2012c) and our CTX crater dating allows these age estimates to be refined. Our large cratered plains area, with a model age of $3.71 \mathrm{Ga}$, lies at the NoachianHesperian boundary, which agrees well with the possible presence of a Noachian-Hesperian contact within this area (Scott and Tanaka, 1986). Although the exact sequence of subsidence causing trough formation both here and in the wider Valles Marineris region was likely complicated (Andrews-Hanna, 2012c), the smallerarea model ages derived here suggest that the plains surrounding the Fan 2 trough might have been emplaced before those surrounding the Fan 1 trough. However, due to the limited areal coverage, we are cautious in discriminating between the exact order of trough formation, but instead concentrate on the overall age of this region. Discounting possible subsequent resurfacing events, the plains material surrounding the study troughs date from the Late Noachian through the Hesperian to the Mid-Amazonian. Given that previous estimates of trough formation are of the order of $\sim 10 \mathrm{Ma}$, and much shorter than timescales for the sedimentary infilling (Andrews-Hanna, 2012c), we can confidently use the age of the plains as maximum ages of the features within the troughs that have formed subsequently. Hence, the fans and phyllosilicate-rich deposits studied here have a probable age of somewhere between the Noachian-Hesperian boundary and the Early-Amazonian.

\subsection{Depositional environment}

Our results suggest that the stepped fans in this study can be best explained by a consistent mechanism that combines several of the previous working hypotheses. We propose a two-stage sequence for formation of the fans and phyllosilicates in this region, involving (1) early shallow standing water (i.e. a lake or playa) with associated fluvial-deltaic processes in the trough, and (2) a later period with little to no deposition in the trough but alluvial processes active on the fan (Fig. 14). We also suggest that subsequent aeolian erosion is mainly responsible for the final stepped appearance of the fans.

\subsubsection{Environment of lower fan deposition}

At least in the early history of the fill succession, standing water was probably present, at least episodically, in the base of the troughs, as suggested in particular by the mineralogy of the LTDs, the fine grain sizes in both LTDs and fans, and the possible presence of low ( $\sim 10 \mathrm{~m}$ scale) delta topset-foreset stratal geometry in Fan 1 at the lowest trough elevations. The cross-trough gradients of the most distal parts of Fan 1 also trend to zero, consistent with progradation over a lake or playa deposit. It is also likely that the trough floor was at times mostly dry (i.e. a playa), as indicated by the interfingering of ridged deposits from the fans among the LTDs, although it is possible that cycles of progradation could also cause the interfingering. On Fan 2, the lower stratigraphy is interpreted to have been dominated by relatively coarser grained channel or braided (e.g. McPherson et al., 1987) deposits (now topographically inverted) set among relatively finer grained overbank deposits, all the way to the toe of the fan. This pattern suggests a more fluvial style to the depositional processes on the fan top. On Fan 1, the lower stratigraphy appears to have been a more sheet-like fluvial system in nature. This variation in stratigraphic architecture is likely related to the nature of the fluvial system together with differences in grain size distribution of supplied sediments.

Our final line of evidence of baselevel control by ponding water at the foot of the fans comes from the consistency of the height of the transition from the ridged to stepped facies in Fan 2 with the top of the LTD deposits on the opposite wall. The intimate relationship between the proximal fan and the distal LTDs is demonstrated by the interfingering of the two in the toe of the fan, and it is apparent that once the facies transition occurred, deposition of the LTDs terminated. We interpret this to indicate that once deposition of stepped facies begins on the fans, neither substantial quantities of sediment or water are reaching the axis of the trough. It also demonstrates that there cannot have been any substantial depth to the lake in the valley axis. Based on the sedimentology (presence of fragments of LTDs on the northern trough wall; proximal-distal facies equivalence between the ridged fan units and the LTDs) the geomorphology (level surfaces between the LTD top and the ridged-to-stepped fan transition), and our HiRISE crater counts (very sparse craters at elevations below the level of the top of the LTDs), we interpret that at the time of the transition from the ridged to stepped facies on the fan, the entire floor of the trough around Fan 2 would have been filled with LTDs. This material has subsequently been eroded from the trough floor and removed from the system, presumably by aeolian processes, as this sediment no longer seems to appear anywhere inside the trough. This also demonstrates the almost entirely fine-grained nature of the LTD sediments (and the sediments surrounding the channels within the fan), such that they can be removed to significant extents by the wind, as suggested at other large-scale interior layered deposits (e.g. Kite et al., 2013a; Grindrod and Warner, 2014).

\subsubsection{Environment of upper fan deposition}

The evidence for a gap in the time of formation (i.e. small crater densities and erosional differences; collapse events in LTDs but not the fan deposits) from digitate to stepped deposits in the fans can be interpreted as synchronous with a change in sedimentation in the trough, and thus representing a fundamental change in the boundary conditions of the system. On Earth, one of the most common methods of producing a stepped sedimentary deposit is as a progressively backstepping delta, through autoretreat of the delta front in a system characterized by rising water level (e.g. Muto, 2001; Muto and Steel, 2001; Parker and Muto, 2003). This process produces primary stepped layers through a rising lake level at the same time as a constant or declining sedimentation rate. This process of base-level rise has also previously been invoked specifically for the formation of Fan 1, with the stepped deposits representing a succession of stacked deltas (Weitz et al., 2006). In addition, both experimental (Kraal et al., 2008; de Villiers et al., 2013) and numerical (Kleinhans et al., 2010) studies have suggested that similar steep-stepped deltas can form in single, rapid events both on Earth and Mars, again within a system characterized rising water level that nearly completely fills the basin with water.

The main argument against having a water level that once reached at least to the top of the fan deposits (or possibly higher) is the lack of supporting evidence, such as erosional, depositional, 


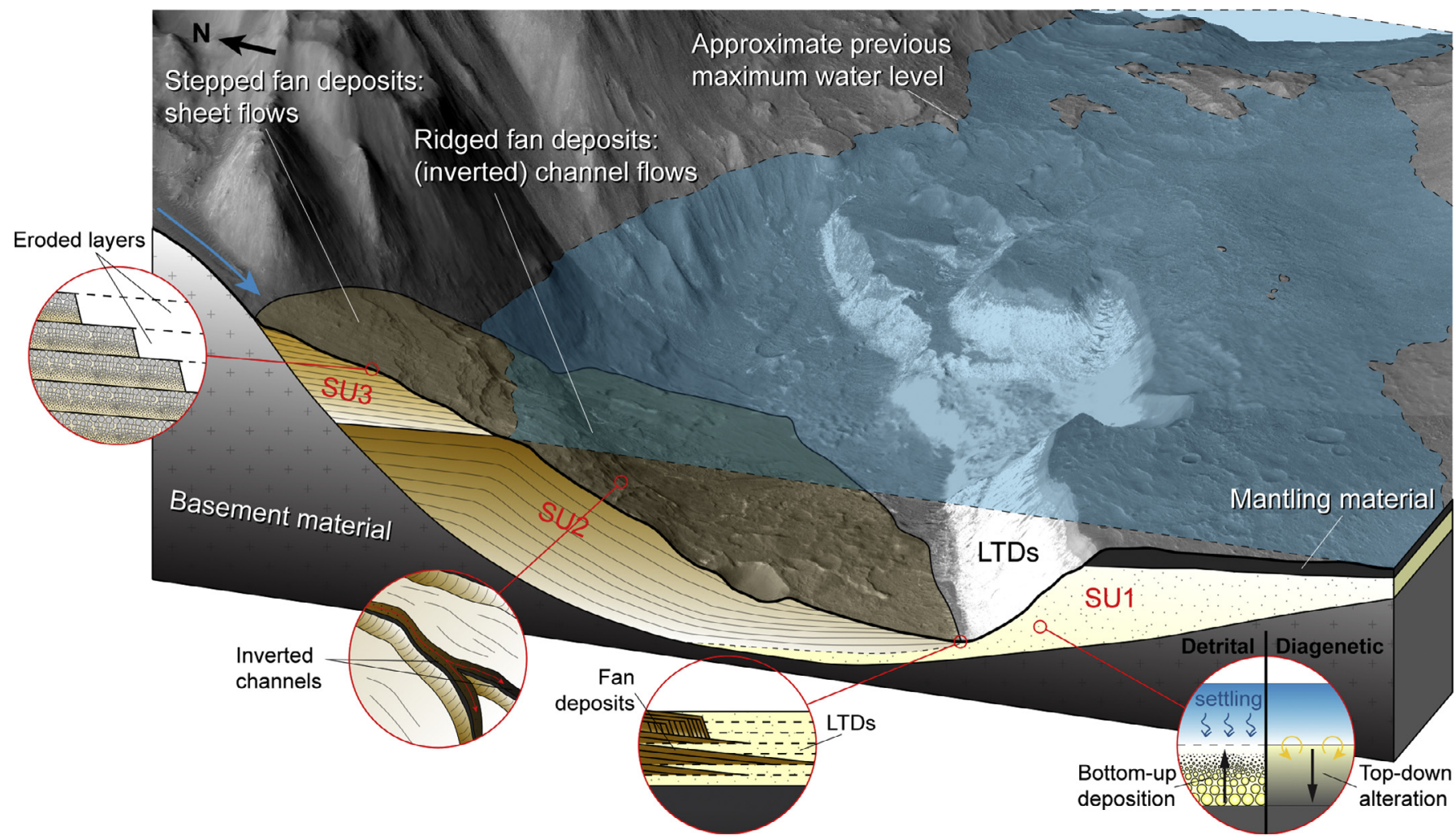

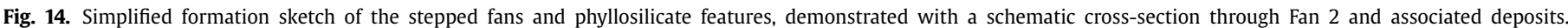

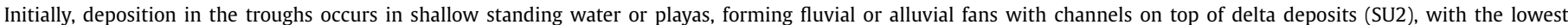

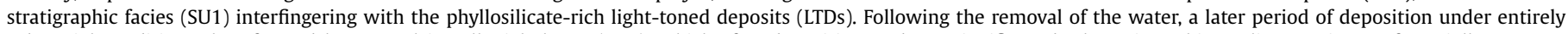

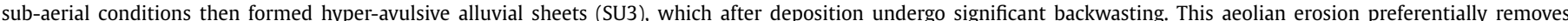

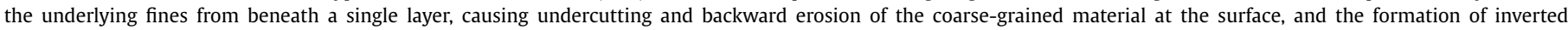
channels in the distal fan deposits.

or alteration horizons, in the walls of the troughs. But, as noted by Weitz et al. (2006), the walls of the troughs are likely unstable and prone to collapse and talus formation, making it possible for evidence of previous shorelines to be removed and/or buried. However, extensive layered deposits are present around the edge of the base of the troughs, and occur only at a height that coincides with the lower stratigraphy ridged deposits. Given that any process(es) capable of removing shoreline evidence in the trough walls could also remove the adjacent lower-lying and older layered deposits, then we suggest that it is unnecessary to invoke a high water level in the troughs and that the upper stepped deposits of these fans do not need standing water to explain their formation. Other stepped deposits not associated with fan-like features occur elsewhere in the Fan 2 trough, but not at the same elevation as in the fan itself. Instead, the top of smaller ( $200-700 \mathrm{~m}$ width) stepped deposits on the northern trough wall (Fig. 2b) occur at elevations that are up to $\sim 100-200 \mathrm{~m}$ above or below that of the top surface of Fan 2; larger, trough-filling layered material (Fig. 2b) occurs entirely at lower elevations, similar to those in the lower fan deposits.

Overall, unlike the lower fan deposits, supporting evidence for a deltaic origin of the upper deposits of our study fans must have either been removed (shorelines on the trough walls) or buried (fan avulsion nodes), although it is important to note that experimental (Kraal et al., 2008; de Villiers et al., 2013) and numerical models (Kleinhans et al., 2010), in addition to interpretations of other stepped fans on Mars (e.g. Hauber et al., 2013) suggest that deltas are capable of producing such stepped deposits.

Instead, we interpret the stepped appearance of our fans to be secondary in nature, formed predominantly through wind erosion of more extensive sub-parallel layers, as suggested by (1) the se- lective erosion of fines from beneath more coarse-grained layers at both fans, (2) the curving of the steps into the small channels at Fan 1, (3) the steps at Fan 2 cross-cutting small channels, and (4) the crater retention data that suggests significant surface modification. The selective erosion of fine-grained material from below more coarse-grained, possibly bouldery, horizons has been interpreted as evidence of inverse grading in these layers, indicative of flash-flood episodes on the Earth (e.g. Postma and Drinia, 1993) or wave-generated collapse in fan-deltas (e.g. Lønne and $\mathrm{Ne}-$ mec, 2004). Under our scenario, the steep scarps of the stepped layers are formed through the aeolian erosion of the fine-grained deposits, undercutting the coarser beds and causing the headward erosion of each layer. The occurrence of the small-scale, incised channels and associated deposits on top of the fans show that some significant fluvial activity continued after the formation of the main part of Fan 1 and Fan 2, In fact, the deposits at the end of the small channel in the west of Fan 1 occur on the large stepped fan itself, and so are strong evidence for sub-aerial alluvial processes that mimic our preferred formation mechanism, albeit at a smaller scale. The curving of the stepped layers into the incised channels at Fan 1 and the steps cross-cutting the small incised channel at Fan 2 demonstrates that the layers have been subject to substantial aeolian erosion after depositional and fluvial activity had ceased. Although stepped deposits form a significant minority of fans on Mars, similar late stage fluvial incision is also evident in at least two other stepped fans $\left(35.3^{\circ} \mathrm{N}, 350.6^{\circ} \mathrm{E} ; 31.6^{\circ} \mathrm{N}, 346.9^{\circ} \mathrm{E}\right)$, which could be indicative of similar processes to those proposed at our study fans. In essence, the stepped fan surfaces that we observe today are predominantly an erosional, rather than a depositional surface. 


\subsubsection{Mass balance assessment}

We derive evidence to support our formation scenario at Fan 1 by looking at the relative volumes of the channels, troughs and fan deposits. At Fan 1 the volume of the well-defined inner channel is $\sim 26 \mathrm{~km}^{3}$; the volume of the less well-defined broad channel that extends further to the south-west is $\sim 62 \mathrm{~km}^{3}$. The volume of the trough of Fan 1 at the base level of the channel entrance is about an order of magnitude larger than the channel, at $\sim 400 \mathrm{~km}^{3}$. The volume of the channel below the knickpoint is $8 \mathrm{~km}^{3}$-comparable to the volume of Fan $1\left(\sim 6 \mathrm{~km}^{3}\right)$. From these measurements we can make three main points: (1) the total channel erosion volume is much greater than that of Fan 1, which implies more material has been delivered to the trough than is in the fan alone, (2) the trough is large enough to take all of the erosive material from the channel, and (3) the stepped fan deposits probably only represent the deposition of material from the knickpoint erosion phase. The knickpoint in the channel leading to Fan 1 could be indicative of (1) a change in the bedrock properties, or (2) a drop in the base level of water in trough. Given that there is no obvious change in lithology in the trough or channel walls, but evidence to support at least some water level change in the trough, we favor the latter interpretation, which is inconsistent with a rising water level. An additional difficulty with a deltaic origin for the entire fan is the requirement that significant volumes of water rapidly fill the $\sim 3.4 \mathrm{~km}$ deep trough at the same time that a relatively small channel feeds sediment into the basin. The total volume of the channel and stepped fan is much lower than the volume of water that is required to fill the basin, even assuming large water to sediment ratios. This implication requires additional water besides that delivered by the channel to fill the basin, such as groundwater influx from a regional aquifer. In the Coprates Catena case here, as well as in other stepped fan systems on Mars, the source of the fluvial channel is distal to the depositional trough. Stepped fan systems in Xanthe Terra for example are sourced by fluvial systems that are hundreds of kilometers in length (Hauber et al., 2013). The outflow source of water from the headwalls of these channels cannot be genetically tied with any certainty to a water source that would fill the basin at the same time as sediment was delivered. Similar comparisons are difficult at Fan 2 due to the lack of any obvious channels terminating in the associated trough. However, the volume of the trough from the top of Fan 2 is $\sim 22 \mathrm{~km}^{3}$, following the general trend of features at Fan 2 being much smaller than those at Fan 1, despite having undergone apparently similar processes.

\subsection{Origin of hydrous phases}

The origin of the phyllosilicate mineral phases in the LTDs in both troughs also contributes toward understanding the formation scenario at these locations. Ehlmann et al. (2013) describe seven different formation settings for phyllosilicates from a basaltic precursor material: (1) near-surface pedogenesis, (2) near-surface basin, (3) hydrothermal (volcanic), (4) hydrothermal (impact), (5) diagenesis, (6) metamorphism, and (7) magmatism. Although it is not possible to definitively determine the source location of the phyllosilicates in our study region, it is possible to establish which alteration process(es) best fit the sedimentary evidence in this region. There are three main possible sources for the alteration phases within the context of our study region: (1) they are original Noachian-aged down-faulted layers that correspond to those deposits in the upper walls and cratered plains outside the troughs, (2) they formed outside the trough and were transported and deposited in the base of the troughs, and (3) they formed in situ in the troughs. Given the lack of evidence for major trough-related faulting in the LTDs or other surficial deposits, and the likely formation of the LTDs after formation of the trough (and apparently overlapping with deltaic or fan processes), it is unlikely that the
LTDs are down-faulted layers from above. The Fe-Mg phyllosilicate signature of the LTDs matches well with that of the wall LTDs, rather than the Al phyllosilicates in the plains outside the trough, and therefore we could only consider this as a local detrital source. Using a conservative average thickness of $200 \mathrm{~m}$, the volume of the exposed LTDs in the trough of Fan 2 is $\sim 1 \mathrm{~km}^{3}$, whereas a more realistic volume of $\sim 10 \mathrm{~km}^{3}$ can be estimated by assuming that LTDs underlie the dark mantling material in the south of the trough. If the LTDs once filled the entire base of the trough and have since been removed then we would expect the LTD volume to be about $20-30 \mathrm{~km}^{3}$. The average thickness of the exposed wall LTDs is $\sim 50 \mathrm{~m}$, which would require an area $\sim 200-600 \mathrm{~km}^{2}$, or about one-third to over one-half of the trough area, to produce an equivalent volume to the LTDs in the base. We do not consider this to be an unreasonable transport volume, but it would require constant wall erosion and deposition throughout trough formation whereas it appears that the bulk of the troughs had formed before deposition, both in sub-aqueous and sub-aerial environments.

In situ formation of the LTDs fits well with the concurrent formation of the putative initial delta deposits in standing water in the troughs, and also with detailed study of the change in chemistry observed in the LTDs in the east of the Fan 1 trough (Grindrod et al., 2012). At those LTDs, Grindrod et al. (2012) not only saw Al smectites as the main hydroxylated alteration phase, suggestive of an open water system near the surface (e.g. Ehlmann et al., 2011), but also stratigraphically-higher sulfates and hydrated silica phases, supportive of formation in a near-surface basin (Ehlmann et al., 2013). In contrast, in the LTDs associated with Fan 2, we see little to no evidence for any alteration mineralogies other than Fe-Mg smectites, which according to the framework of Ehlmann et al. (2011) suggest subsurface closed water systems. Given the geomorphologic evidence suggesting that LTD emplacement was concurrent with a shallow lake environment in the trough base, then the presence of $\mathrm{Fe}-\mathrm{Mg}$ phyllosilicates phases here can be explained by (1) limited ion transport in a low water-rock ratio environment (Ehlmann et al., 2011), perhaps isolated from the lake and atmosphere by the mantling material or a frozen surface, or (2) top-down pedogenesis from percolating water (Le Deit et al., 2012) with upper Al phases limited or removed. It is more difficult at Fan 2 to rule out detrital deposition in the trough as the source of the LTDs due to the lack of a well-defined alteration sequence, however the plains outside the troughs in this region contain exposures of $\mathrm{Al}$ phyllosilicates overlying Fe-Mg phyllosilicates (Le Deit et al., 2012). Given that the Fe$\mathrm{Mg}$ deposits are exposed predominantly by impacts and troughs rather than fluvial erosion, and the lack of $\mathrm{Al}$ phases in our trough that would have to be removed to access the $\mathrm{Fe}-\mathrm{Mg}$ phases below, we tentatively prefer an in situ origin for the alteration phases in the LTDs in both troughs. However, we note that determining the exact source of the phyllosilicate chemistries in both our study troughs, and indeed elsewhere on Mars, remains problematic (e.g. Milliken and Bish, 2010; Bristow and Milliken, 2011), and so we cannot rule detrital contributions to the alteration phases in our study region.

\subsection{Implications for sedimentary and aqueous processes on Mars}

We have identified evidence for fluvial activity involving different geomorphic and geochemical processes. These results fit well into the general framework of at least one, possibly several, temporally-discreet increases in surface fluvial activity since the Noachian-Hesperian transition, possibly as late as the Early Amazonian (e.g. Irwin et al., 2005; Quantin et al., 2005; Fassett and Head, 2007, 2008; Fassett et al., 2010; Hynek et al., 2010; Warner et al., 2010b; Grant and Wilson, 2012; Parsons et al., 2013). The lack of an obvious source region for the channels that end in the 
troughs, and led to the formation of the fans and LTDs, can be explained by volcanic melting of surface or ground ice (Weitz et al., 2006), or snowpack accumulation and melting (Kite et al., 2013b; Parsons et al., 2013). A precipitation-derived source for the fluvial activity may be initially difficult to justify due to the lack of evidence of catchment and drainage networks in this region. However, recent work on amphitheater-headed terrestrial bedrock channels that are similar in morphology to many of the channels that enter Valles Marineris (including the channel sourcing Fan 1) indicates that bedrock incision can be predominately driven by overland flow (e.g. Lamb and Fonstad, 2010) and knickpoint retreat, with little contribution from groundwater sapping or little evidence of erosion upstream of the headwall. This process is particularly relevant in channels that are wholly contained within fractured bedrock and extend off of pre-existing escarpments, such as is likely the case for our study channels. In these terrestrial systems, toppling failure of a fractured knickpoint headwall that initiates at an escarpment causes relatively rapid upstream knickpoint migration during high magnitude flows. For the bedrock canyons that occur on the basaltic-dominated Snake River escarpment in southern Idaho (Lamb et al., 2008) there is little evidence for erosion or channel formation upstream of the preserved knickpoints, as most of the erosive work occurred at the headwall. For the channel that sources Fan 1, the observed knickpoint provides evidence for a similar process of canyon formation. By analogy to the terrestrial systems, this suggests the possibility that precipitation and overland flow may have provided the water necessary to form the bedrock channels in our study without leaving significant evidence for a drainage network on the extremely flat upstream plains.

One of the most important observations of our study is that we can stratigraphically project sedimentary facies forming Fan 2 into the LTDs that contain extensive phyllosilicates (Fig. 4b). This finding effectively means that we can say with some confidence that water was present at approximately the same time as extensive phyllosilicate deposition or formation, something which has been difficult to determine at other sites with good exposures of phyllosilicates, such as Jezero Crater (e.g. Ehlmann et al., 2008; Schon et al., 2012). Therefore these features would make interesting targets for future studies, particularly in situ exploration of former lake environments. Perhaps one of the more intriguing results from our study is the observation of fluvial activity during the Hesperian period that led to the formation, or at least deposition, of phyllosilicate phases. Although episodic fluvial activity at this time has been identified in an increasing number of locations (e.g. Irwin et al., 2005; Parsons et al., 2013), it is difficult to reconcile the identification of Hesperian-aged phyllosilicates with the framework of Bibring et al. (2006). It is of course possible that Hesperian-era fluvial activity simply transported and deposited Noachian-aged phyllosilicates, but the closed trough of Fan 1 also contains LTDs rich in a succession of clay-rich deposits with overlying sulfate or opaline minerals, suggestive of in situ formation (Grindrod et al., 2012). Without being certain of in situ formation of these alteration phases, it is difficult to determine their impact on our understanding of the history of water on Mars. However, our identification of two adjacent Hesperian trough systems, both with the presence of likely fluvial deposits and phyllosilicates that can be linked in time presents a strong case for another exception to the framework of Bibring et al. (2006), in addition to those suggested by Murchie et al. (2009b).

Given that both of our study troughs are closed basins, any water present must have either drained away as groundwater and/or evaporated (sublimated if frozen). If drainage occurred by infiltration as groundwater, then given a regional sub-surface hydrological system (Andrews-Hanna et al., 2007), we could expect to find further deposits at lower elevations where the groundwater emerges and precipitation of solute phases occurs upon diffusive contact with the atmosphere (e.g. Grindrod and Balme, 2010). Although approximately $300 \mathrm{~km}$ to the north-west, the perched LTDs identified in Southern Coprates Chasma (Fueten et al., 2011), offer a possible example of this type of feature. If drainage was sufficiently slow, then evaporative processes could dominate leading to the formation of a frozen lake surface. However, our putative lake areas are several orders of magnitude smaller than those proposed in the large chaos regions in Valles Marineris (e.g. Warner et al., 2013), and so as a result any evaporative impact on local atmosphere, snowfall and snowmelt would likely be less significant in our study region (c.f. Kite et al., 2011). Although our study troughs and related fans are relatively small in area, our observations, including channelized overland flow, lacustrine deposition, and in situ diagenesis, add to the growing recent evidence for episodically widespread fluvial processes in this equatorial region of Mars during the Hesperian to Amazonian (e.g. Harrison and Chapman, 2008; Metz et al., 2009; Lucchitta, 2010; Fueten et al., 2011; Grant and Wilson, 2012; Warner et al., 2010b, 2013; Williams et al., 2013; Grotzinger et al., 2014, 2015).

\section{Conclusions}

Our morphologic, mineralogical and chronologic constraints may suggest that sedimentary fans and related phyllosilicate deposits preserved in adjacent troughs in the Coprates Catena region of south east Valles Marineris formed by similar processes. The simplest hypothesis to explain our observations is a two stage process, whereby deposition in the troughs first occurs into relatively shallow standing water, forming fluvial or alluvial fans that terminate in delta deposits and interfinger with interpreted lacustrine facies, followed by a later period of deposition under sub-aerial conditions, forming alluvial fan deposits only. Subsequent aeolian erosion then caused modification of both deposit types. The channelized deltaic deposits underwent relief inversion of channel-form coarser-grained units during erosion, leaving ridged digitate features. In the stepped fan deposits, this aeolian erosion preferentially removed the underlying fines from beneath a single layer, causing undercutting and backward erosion of the coarse-grained material at the surface. We therefore suggest that the distinctive stepped appearance of these fans is the result of this aeolian erosion, and is not a primary depositional feature. We suggest that the period of standing water also coincides with the timing of phyllosilicate formation in these troughs, and although it is not possible to determine whether these clays are detrital or formed in situ, we have found evidence in both troughs that could support both diagenetic or detrital processes occurring in the troughs. This combined formation framework for stepped fans and phyllosilicates can also explain other similar features on Mars, and adds to the growing evidence of fluvial activity in the equatorial region of Mars during the Hesperian and Early Amazonian. The definite identification of equivalent facies in the fans and phyllosilicates is rare on Mars, and as such these and other similar deposits offer important targets for possible future missions.

\section{Acknowledgments}

P.M.G. was funded by the UK Space Agency (Aurora Fellowship grants ST/J002127/1; ST/J005215/1; ST/L00254X/1). The stereo DTM and CRISM processing was carried out at the UK NASA RPIF at University College London. We thank Annie Howington-Kraus at the USGS for help in producing stereo DTMs, and the CTX, HiRISE and CRISM teams for making the data available, and providing tools to aid in their processing. We also thank Maarten Kleinhans and Cathy Quantin-Nataf for detailed reviews that significantly improved the manuscript, and Jeffrey Johnson for editorial handling. 


\section{References}

Anderson, R.C., Dohm, J.M., Golombek, M.P., Haldemann, A.F.C., Franklin, B.J., Tanaka, K.L., Lias, J., Peer, B., 2001. Primary centers and secondary concentrations of tectonic activity through time in the western hemisphere of Mars. J. Geophys. Res. 106, 20,563-20,585. doi:10.1029/2000JE001278.

Andrews-Hanna, J.C., 2012a. The formation of Valles Marineris: 1. Tectonic architecture and the relative roles of extension and subsidence. J. Geophys. Res. 117, E03006. doi:10.1029/2011JE003953.

Andrews-Hanna, J.C., 2012b. The formation of Valles Marineris: 2. Stress focusing along the buried dichotomy boundary. J. Geophys. Res. 117, E04009. doi:10.1029/ 2011JE003954.

Andrews-Hanna, J.C., 2012c. The formation of Valles Marineris: 3. Trough formation through super-isostasy, stress, sedimentation, and subsidence. J. Geophys. Res. 117, E06002. doi:10.1029/2012JE004059.

Andrews-Hanna, J.C., Phillips, R.J., Zuber, M.T., 2007. Meridiani Planum and the global hydrology of Mars. Nature 446, 163-166. doi:10.1038/nature05594.

Baker, V.R., Partridge, J.B., 1986. Small Martian valleys-pristine and degraded morphology. J. Geophys. Res. 91, 3561-3572. doi:10.1029/JB091iB03p03561.

Bibring, J.-P., et al., 2006. Global mineralogical and aqueous Mars history derived from OMEGA/Mars Express data. Science 312, 400-404. doi:10.1126/science. 1122659 .

Bishop, J.L., et al., 2009. Mineralogy of Juventae Chasma: sulfates in the lighttoned mounds, mafic minerals in the bedrock, and hydrated silica and hydroxylated ferric sulfate on the plateau. J. Geophys. Res. 114, E00D09. doi:10.1029/ 2009JE003352.

Bristow, T.F., Milliken, R.E., 2011. Terrestrial perspective on authigenic clay mineral production in ancient martian lakes. Clay. Clay Miner. 59, 339-358. doi:10.1346/ CCMN.2011.0590401

Cabrol, N.A., Grin, E.A., 1999. Distribution, classification and ages of Martian impact crater lakes. Icarus 142, 160-172. doi:10.1006/icar.1999.6191.

Cabrol, N.A., Grin, E.A., 2001. The evolution of lacustrine environments on early Mars: is Mars only hydrologically dormant? Icarus $149,291-328$. doi:10.1006 icar.2000.6530.

Craddock, R.A., Maxwell, T.A., 1993. Geomorphic evolution of the martian highlands through ancient fluvial processes. J. Geophys. Res. 98, 3453-3468. doi:10.1029/ 92JE02508.

De Villiers, G., Kleinhans, M.G., Postma, G., 2013. Experimental delta formation in crater lakes and implications for interpretation of martian deltas. J. Geophys. Res. doi:10.1002/jgre.20069, in press.

Di Achille, G., Hynek, B.M., 2010. Deltas and valley networks on Mars: implications for a global hydrosphere. In: Cabrol, N.A., Grin, E.A. (Eds.), Lakes on Mars. Elsevier, Amsterdam, pp. 223-248. doi:10.1016/B978-0-444-52854-4.00005-2.

Di Achille, G., Ori, G.G., Reiss, D., Hauber, E., Gwinner, K., Michael, G., Neukum, G., 2006. A steep fan at Coprates Catena, Valles Marineris, Mars, as seen by HRSC data. Geophys. Res. Lett. 33, L07204. doi:10.1029/2005GL025435.

DiBiase, R.A., Limaye, A.B., Scheingross, J.S., Fischer, W.W., Lamb, M.P., 2013. Deltaic deposits at Aeolis Dorsa: sedimentary evidence for a standing body of water on the northern plains of Mars. J. Geophys. Res. doi:10.1002/jgre.20100, in press.

Ehlmann, B.L., et al., 2009. Identification of hydrated silicate minerals on Mars using MRO-CRISM: geologic context near Nili Fossae and implications for aqueous alteration. J. Geophys. Res. 114, E00D08. doi:10.1029/2009JE003339.

Ehlmann, B.L., Mustard, J.F, Fassett, C.I., Schon, S.C., Head, J.W., Des Marais, D.J., Grant, J.A, Murchie, S.L., 2008. Clay minerals in delta deposits and organic preservation potential on Mars. Nat. Geosci 1, 355-358. doi:10.1038/ngeo207.

Ehlmann, B.L., Mustard, J.F., Murchie, S.L., Bibring, J.-P., Meunier, A., Fraeman, A.A., Langevin, Y., 2011. Subsurface water and clay mineral formation during the early history of Mars. Nature 479, 53-60. doi:10.1038/nature10582.

Ehlmann, B.L., Berger, G., Mangold, N., Michalski, J.R., Catling, D.C., Ruff, S.W., Chassefiére, E., Niles, P.B., Chevrier, V., Poulet, F., 2013. Geochemical consequences of widespread clay mineral formation in Mars' ancient crust. Space Sci. Rev. 174, 329-364. doi:10.1007/s11214-012-9930-0.

Fassett, C.I., Head III, J.W., 2005. Fluvial sedimentary deposits on Mars: ancient deltas in a crater lake in the Nili Fossae region. Geophys. Res. Lett. 32, L14201. doi:10.1029/2005GL023456.

Fassett, C.I., Head, J.W., 2007. Valley formation on martian volcanoes in the Hesperian: evidence for melting of summit snowpack, caldera lake formation, drainage and erosion on Ceraunius Tholus. Icarus 189, 118-135. doi:10.1016/j. Icarus.2006.12.021.

Fassett, C.I., Head, J.W., 2008. The timing of martian valley network activity: constraints from buffered crater counting. Icarus 195, 61-89. doi:10.1016/j.icarus. 2007.12.009.

Fassett, C.I., Dickson, J.L., Head, J.W., Levy, J.S., Marchant, D.R., 2010. Supraglacial and proglacial valleys on Amazonian Mars. Icarus 208. doi:10.1016/j.Icarus.2010.02. 021

Flahaut, J., Quantin, C., Clenet, H., Allemand, P., Mustard, J.F., Thomas, P., 2012. Pristine Noachian crust and key geologic transitions in the lower walls of Valles Marineris: insights into early igneous processes on Mars. Icarus 221, 420-435. doi:10.1016/j.icarus.2011.12.027.

Fueten, F., Flahaut, J., Le Deit, L., Stesky, R., Hauber, E., Gwinner, K., 2011. Interior layered deposits within a perched basin, southern Coprates Chasma, Mars: evidence for their formation, alteration, and erosion. J. Geophys. Res. 116, E02003. doi:10.1029/2010JE003695.

Fueten, F., Stesky, R., MacKinnon, P., Hauber, E., Zegers, T., Gwinner, K., Scholten, F., Neukum, G., 2008. Stratigraphy and structure of interior layered deposits in west Candor Chasma, Mars, from High Resolution Stereo Camera (HRSC) stereo imagery and derived elevations. J. Geophys. Res. 113, E10008. doi:10.1029/ 2007JE003053.

Fueten, F., Racher, H., Stesky, R., MacKinnon, P., Hauber, E., McGuire, P.C., Zegers, T. Gwinner, K., 2010. Structural analysis of interior layered deposits in Northern Coprates Chasma, Mars. Earth Planet. Sci. Lett. 294, 343-356. doi:10.1016/j.epsl. 2009.11.004.

Grant, J., Wilson, S., 2012. Late alluvial fan formation in southern Margaritifer Terra, Mars. Geophys. Res. Lett. 38. doi:10.1029/2011GL046,844.

Grindrod, P.M., Balme, M.R., 2010. Groundwater processes in Hebes Chasma, Mars. Geophys. Res. Lett. 37, L13202. doi:10.1029/2010GL044122.

Grindrod, P.M., Fawcett, S.A., 2011. Possible climate-related signals in high-resolution topography of lobate debris aprons in Tempe Terra, Mars. Geophys. Res. Lett. 38, L19201. doi:10.1029/2011GL049295.

Grindrod, P.M., Warner, N.H., 2014. Erosion rate and previous extent of interior layered deposits on Mars revealed by obstructed landslides. Geology 42, 795-798. doi:10.1130/G35790.1.

Grindrod, P.M., West, M., Warner, N.H. Gupta, S., 2012. Formation of an Hesperianaged sedimentary basin containing phyllosilicates in Coprates Catena, Mars. Icarus 218, 178-195. doi:10.1016/j.icarus.2011.11.027.

Grotzinger, J.D., et al., 2011. Mars sedimentary geology: key concepts and outstanding questions. Astrobiology 11, 77-87. doi:10.1089/ast.2010.0571.

Grotzinger, J.D., et al., 2014. A habitable fluvio-lacustrine environment at Yellowknife Bay, Gale Crater, Mars. Science 343, 1242777. doi:10.1126/science.1242777.

Grotzinger, J.D., et al., 2015. Deposition, exhumation, and paleoclimate of an ancient lake deposit, Gale crater, Mars. Science 350. doi:10.1126/science.aac7575, aac7575.

Harrison, K.R., Chapman, M.G., 2008. Evidence for ponding and catastrophic flood in central Valles Marineris. Icarus 198, 351-364. doi:10.1016/j.icarus.2008.08.003.

Hartmann, W.K., 2005. Martian cratering 8; isochron refinement and the chronology of Mars. Icarus 174, 294-320. doi:10.1016/j.icarus.2004.11.023.

Hartmann, W.K., Neukum, G., 2001. Cratering chronology and the evolution of Mars. Space Sci. Rev. 96, 165-194. doi:10.1023/A:1011945222010.

Hauber, E., Gwinner, K., Kleinhans, M., Reiss, D., Di Achille, G., Ori, G.G., Scholten, F., Marinangeli, L., Jaumann, R., Neukum, G., 2009. Sedimentary deposits in Xanthe Terra: implications for the ancient climate on Mars. Plan. Space Sci. 944-957. doi:10.1016/j.pss.2008.06.009

Hauber, E., Platz, T., Reiss, D., Le Deit, L., Kleinhans, M.G., Marra, W.A., de Haas, T., Carbonneau, P., 2013. Asynchronous formation of Hesperian and Amazonianaged deltas on Mars and implications for climate. J. Geophys. Res. 118, 15291544. doi:10.1002/jgre.20107.

Hynek, B.M., Beach, M., Hoke, M.R.T., 2010. Updated global map of Martian valley networks and implications for climate and hydrologic processes. J. Geophys. Res. 115. doi:10.1029/2009JE003548.

Irwin, R.P., Howard, A.D., Craddock, R.A., Moore, J.M., 2005. An intense terminal epoch of widespread fluvial activity on early Mars: 2 . Increased runoff and paleolakes development. J. Geophys. Res. 110, E12S15. doi:10.1029/2005JE002460.

Ivanov, B.A., 2001. Mars/Moon cratering rate ratio estimates. Space Sci. Rev. 96, $87-$ 104. doi:10.1023/A:1011941121102

Jaumann, R., et al., 2007. The high-resolution stereo camera (HRSC) experiment on Mars Express: instrument aspects and experiment conduct from interplanetary cruise through the nominal mission. Planet. Space Sci. 55, 928-952. doi:10.1016| j.pss.2006.12.003.

Jerolmack, D.J., Mohrig, D., Zuber, M.T., Byrne, S., 2004. A minimum time for the formation of Holden Northeast fan, Mars. Geophys. Res. Lett. 31, L21701. doi:10 1029/2004GL021326.

Kite, E.S., Lewis, K.W., Lamb, M.P., Newman, C.E., Richardson, M.I., 2013a. Growth and form of the mound in Gale Crater, Mars: slope wind enhanced erosion and transport. Geology 41, 543-546. doi:10.1130/G33909.1.

Kite, E.S., Halevy, I., Kahre, M.A., Wolff, M.J., Manga, M., 2013b. Seasonal melting and the formation of sedimentary rocks on Mars, with predictions for the Gale Crater mound. Icarus 223, 181-210. doi:10.1016/j.icarus.2012.11.034

Kite, E.S., Rafkin, S., Michaels, T.I., Dietrich, W.E., Manga, M., 2011. Chaos terrain, storms, and past climate on Mars. J. Geophys. Res. 116, E10002. doi:10.1029/ 2010JE003792.

Kirk, R.L., Howington-Kraus, E., Redding, B., Galuszka, D., Hare, T.M., Archinal, B.A., Soderblom, L.A., Barrett, J.M., 2003. High-resolution topomapping of candidate MER landing sites with Mars Orbiter Camera narrow-angle images. J. Geophys. Res. 108, 8088. doi:10.1029/2003JE002131, E12

Kirk, R.L., et al., 2008. Ultra-high-resolution topographic mapping of Mars with MRO HiRISE stereo images: meter-scale slopes of candidate Phoenix landing sites. J. Geophys. Res. 113, E00A24. doi:10.1029/2007JE003000.

Kleinhans, M.G., van de Kasteele, H.E., Hauber, E., 2010. Palaeoflow reconstruction from fan delta morphology on Mars. Earth Planet. Sci. Lett. 294, 378-392. doi:10.1016/j.epsl.2009.11.025

Kraal, E.R., van Dijk, M., Postma, G., Kleinhans, M.G., 2008. Martian steppeddelta formation by rapid water release. Nature 421, 973-976. doi:10.1038| nature06615.

Lamb, M.P., Fonstad, M.A., 2010. Rapid formation of a modern bedrock canyon by a single flood event. Nat. Geosci. 3, 477-481. doi:10.1038/NGEO894.

Lamb, M.P., Dietrich, W.E., Aciego, S.M., DePaolo, D.J., Manga, M., 2008. Formation of Box Canyon, Idaho, by megaflood: implications for seepage erosion on Earth and Mars. Science 320, 1067-1070. doi:10.1126/science.1156630.

Le Deit, L., Flahaut, J., Quantin, C., Hauber, E., Mège, D., Bourgeois, O., Gurgurewicz, J., Massé, M., Jaumann, R., 2012. Extensive surface pedogenic alteration of the Martian Noachian crust suggested by plateau phyllosilicates around Valles Marineris. J. Geophys. Res. 117, E00J05. doi:10.1029/2011JE003983. 
Lønne, I., Nemec, W., 2004. High-arctic fan delta recording deglaciation and environment disequlibrium. Sediment. 51, 553-589. doi:10.1111/j.1365-3091.2004. 00636.x.

Lucas, A., Mangeney, A., Mège, D., Bouchut, F., 2011. Influence of the scar geometry on landslide dynamics and deposits: application to Martian landslides. J. Geophys. Res. 116, E10001. doi:10.1029/2011JE003803.

Lucchitta, B.K., 2010. Lakes in Valles Marineris. In: Cabrol, N.A., Grin, E.A. (Eds.), Lakes on Mars. Elsevier, Amsterdam, pp. 111-161. doi:10.1016/ B978-0-444-52854-4.00005-2.

Malin, M.C., Edgett, K.S., 2003. Evidence for persistent flow and aqueous sedimentation on early Mars. Science 302, 1931-1934. doi:10.1126/science.1090544.

Malin, M.C., et al., 2007. Context camera investigation on board the Mars Reconnaissance Orbiter. J. Geophys. Res. 112, E05S04. doi:10.1029/2006JE002808.

Massé, M., Bourgeois, O., Le Mouélic, S., Verpoorter, C., Spiga, A., Le Deit, L., 2012. Wide distribution and glacial origin of polar gypsum on Mars. Earth Planet. Sci. Lett. 317-318, 44-55. doi:10.1016/j.epsl.2011.11.035.

Masursky, H., 1973. An overview of geologic results from Mariner 9. J. Geophys. Res. 78, 4009-4038. doi:10.1029/JB078i020p04009.

McEwen, A.S., et al., 2007. Mars Reconnaissance Orbiter's High Resolution Imaging Science Experiment (HiRISE). J. Geophys. Res. 112, E05S02. doi:10.1029/ 2005JE002605

McGuire, P.C., et al., 2009. An improvement to the volcano-scan algorithm for atmospheric correction of CRISM and OMEGA spectral data. Planet. Space Sci. 57, 809-815. doi:10.1016/j.pss.2009.03.007.

McPherson, J.G., Shanmugan, G., Moiola, R.J., 1987. Fan-deltas and braid deltas: varieties of coarse-grained deltas. Geol. Soc. Am. Bull. 99, 331-340 doi:10.1130/0016-7606(1987)99<331:FABDVO>2.0.CO;2.

Metz, J.M., Grotzinger, J.P., Mohrig, D., Milliken, R., Prather, B., Pirmez, C., McEwen, A.S., Weitz, C.M., 2009. Sublacustrine depositional fans in southwest Melas Chasma. J. Geophys. Res. 114, E10002. doi:10.1029/2009JE003365.

Michael, G.G., Neukum, G., 2010. Planetary surface dataing from crater sizefrequency distribution measurements: partial resurfacing events and statistical age uncertainty. Earth Planet. Sci. Lett. 294, 223-2239. doi:10.1016/j.epsl.2009. 12.041 .

Milliken, R.E., Bish, D.L., 2010. Sources and sinks of clay minerals on Mars. Phil. Mag. 90, 14-28. doi:10.1080/14786430903575132.

Moore, J.M., Howard, A.D., 2005. Large alluvial fans on Mars. J. Geophys. Res. 110, E04005. doi:10.1029/2004JE002352.

Morgan, F., Seelos, F., Murchie, S., 2009. CAT tutorial. Presented at CRISM Workshop Held in Conjunction with the 40th Lunar and Planetary Science Conference. Lunar and Planetary Institute, Woodlands, TX 22 March.

Morgan, A.M., Howard, A.D., Hobley, D.E.J., Moore, J.M., Dietrich, W.E., Williams, R.M.E., Burr, D.M., Grant, J.A., Wilson, S.A., Matsubara, Y., 2014. Sedimentology and climatic environment of alluvial fans in the martian Saheki crater and a comparison with terrestrial fans in the Atacama Desert. Icarus 229, 131-156. doi:10.1016/j.icarus.2013.11.007.

Murchie, S., et al., 2007. Compact Reconnaissance Imaging Spectrometer for Mars (CRISM) on Mars Reconnaissance Orbiter (MRO). J. Geophys. Res. 112, E05S03. doi:10.1029/2006JE002682.

Murchie, S., et al., 2009a. Evidence for the origin of layered deposits in Candor Chasma, Mars, from mineral composition and hydrologic modeling. J. Geophys. Res. 114, E00D05. doi:10.1029/2009JE003343.

Murchie, S., et al., 2009b. A synthesis of martian aqueous mineralogy after 1 Mars year of observations from the Mars Reconnaissance Orbiter. J. Geophys. Res. 114, E00D06. doi:10.1029/2009JE003342.

Muto, T., 2001. Shoreline autoretreat substantiated in flume experiment. J. Sediment. Res. 71, 246-254. doi:10.1306/091400710246.

Muto, T., Steel, R.J., 2001. Autostepping during the transgressive growth of deltas: results from flume experiments. Geology 29, 771-774. doi:10.1130/009, doi:17613(2001)029<0771:ADTTGO>2.0.CO;2

Okubo, C.H., 2010. Structural geology of Amazonian-aged layered sedimentary deposits in southwest Candor Chasma, Mars. Icarus 207, 210-225. doi:10.1016/j. icarus.2009.11.012.

Ori, G.G., Marinangeli, L., Baliva, A., 2000. Terraces and Gilbert-type deltas in crater lakes in Ismenius Lacus and Memnonia (Mars). J. Geophys. Res. 105. doi:10. 1029/1999JE001219, 17,629-17,641.

Parente, M., 2008. A new approach to denoising CRISM images. Lunar Planet. Sci. XXXIX Abstract 2528

Parker, G., Muto, T., 2003. 1D numerical model of delta response to rising sea level In: Proceedings of Third IAHR Symposium on River, Coastal and Estuarine Morphodynamics. Barcelona, Spain, pp. 558-570.

Parsons, R.A., Moore, J.M., Howard, A.D., 2013. Evidence for a short period of hydrologic activity in Newton Crater, Mars near the Hesperian-Amazonian transition. J. Geophys. Res. doi:10.1002/jgre.20088, in press.
Pelkey, S.M., et al., 2007. CRISM multispectral summary products: parameterizing mineral diversity in Mars from reflectance. J. Geophys. Res. 112, E08S14. doi:10. 1029/2006JE002831.

Penck, W., 1924. Die Morphologische Analyse (Morphological Analysis of Landforms): J. Engelhorn's Nachfolger, Suttgart. 283 p. English translation by Czech, H. \& Boswell, K.C., London, 1953. St. Martin's Press, New York, p. 429.

Pondrelli, M., Pio Rossi, A., Marinangeli, L., Hauber, E., Gwinner, K., Baliva, A., di Lorenzo, S., 2008. Evolution and depositional environments of the Eberswalde fan delta, Mars. Icarus 197, 429. doi:10.1016/j.icarus.2008.05.018.

Postma, G., Drinia, H., 1993. Architecture and sedimentary facies evolution of a marine, expanding outer-arc half-graben (Crete, late Miocene). Basin Res. 5, 103124. doi: $10.1111 /$ j.1365-2117.1993.tb00060.x.

Quantin, C., Allemand, P., Mangold, N., Dromart, G., Delacourt, C., 2005. Fluvial and lacustrine activity on layered deposits in Melas Chasma, Valles Marineris, Mars. J. Geophys. Res. 110. doi:10.1029/2005JE002440.

Rice, M.S., Gupta, S., Bell, J.F., Warner, N.H., 2011. Influence of fault-controlled topography on fluvio-deltaic sedimentary systems in Eberswalde crater, Mars. Geophys. Res. Lett. 38, L16203. doi:10.1029/2011GL048149.

Rice, M.S., Bell, J.F., Gupta, S., Warner, N.H., Goddard, K., Anderson, R.B., 2013. A detailed geologic characterization of Eberswalde crater, Mars. MARS 8, 15-57. doi:10.1555/mars.2013.0002.

Sharp, R.P., Malin, M.C., 1975. Valleys on Mars. Geol. Soc. Am. Bull. 86, 593-609 doi:10.1130/0016-7606(1975)86<593:COM>2.0.CO;2

Schon, S.C., Head, J.W., Fassett, C.I., 2012. An overfilled lacustrine system and progradational delta in Jezero crater, Mars: implications for Noachian climate. Planet. Space Sci. doi:10.1016/j.pss.2012.02.003, in press.

Schultz, R.A., 1991. Structural development of Coprates Chasma and Western Ophir Planum, Valles Marineris Rift, Mars. J. Geophys. Res. 96, 22777-22792. doi:10. 1029/91JE02556.

Schultz, R.A., 1998. Multiple-process origin of Valles Marineris basins and troughs, Mars. Planet. Space Sci. 46, 827-834. doi:10.1016/S0032-0633(98)00030-0.

Scott, D.H., Tanaka, K.L., 1986. Geologic map of the western equatorial region of Mars. US Geol. Surv. Misc. Invest. Ser. Map, I-1802-A.

Sefton-Nash, E., Catling, D.C., Wood, S.E., Grindrod, P.M., Teanby, N.A., 2012. Topographic, spectral and thermal inertia analysis of interior layered deposits in Iani Chaos, Mars. Icarus 221, 20-42. doi:10.1016/j.icarus.2012.06.036.

Smith, D.E., et al., 1999. The global topography of Mars and implications for surface evolution. Science 284, 1495-1503. doi:10.1126/science.284.5419.1495.

Tanaka, K.L., 1986. The stratigraphy of Mars. J. Geophys. Res. 91, E139-E158. doi:10. 1029/JB091iB13p0E139.

Warner, N., Gupta, S., Calef, F., Grindrod, P., Boll, N., Goddard, K., 2015. Minimum effective area for high resolution crater counting of martian terrains. Icarus 245 198-240. doi:10.1016/j.icarus.2014.09.024.

Warner, N., Gupta, S., Kim, J.-R., Lin, S.-Y., Muller, J.-P., 2010a. Hesperian equatoria thermokarst lakes in Ares Vallis as evidence for transient warm conditions on Mars. Geology 38, 71-74. doi:10.1130/G30579.1.

Warner, N., Gupta, S., Kim, J.-R., Lin, S.-Y., Muller, J.-P., Morley, J., 2010b. Late Noachian to Hesperian climate change on Mars: evidence of episodic warming from transient crater lakes near Area Vallis. J. Geophys. Res. 115, E06013. doi:10.1029/2009JE003522

Warner, N., Gupta, S., Kim, J.-R., Lin, S.-Y., Muller, J.-P., 2010c. Retreat of a giant cataract in a long-lived (3.7-2.6 Ga) martian outflow channel. Geology 38, 791794. doi:10.1130/G31268.1

Warner, N.H., Sowe, M., Gupta, S., Dumke, A., Goddard, K., 2013. Fill and spill of giant lakes in the eastern Valles Marineris region of Mars. Geology doi:10.1130/ G34172.1, in press.

Weitz, C.M., Irwin, R.P., Chuang, F.C., Bourke, M.C., Crown, D.A., 2006. Formation of a terraced fan deposit in Coprates Catena, Mars. Icarus 184, 436-451. doi:10.1016/ j.icarus.2006.05.024.

Weitz, C.M., Milliken, R.E., Grant, J.A., McEwen, A.S., Williams, R.M.E., Bishop, J.L., Thomson, B.J., 2010. Mars Reconnaissance Orbiter observations of light-toned layered deposits and associated fluvial landforms on the plateaus adjacent to Valles Marineris. Icarus 205, 73-102. doi:10.1016/j.icarus.2009.04.017.

Williams, R.M.E., Zimbelman, J.R., Johnston, A.K., 2006. Aspects of alluvial fan shape indicative of formation process: a case study in southwestern California with application to Mojave Crater fans on Mars. Geophys. Res. Lett. 33, L10201. doi:10.1029/2005GL025618.

Williams, R.M.E., Rogers, A.D., Chojnacki, M., Boyce, J., Seelos, K.D., Hardgrove, C., Chuang, F., 2011. Evidence for episodic alluvial fan formation in far western Terra Tyrrhena, Mars. Icarus 211, 222-237. doi:10.1016/j.icarus.2010.10.001.

Williams, R.M.E., et al., 2013. Martian fluvial conglomerates at Gale Crater. Science 340, 1068-1072. doi:10.1126/science.1237317.

Witbeck, N.E., Tanaka, K.L., Scott, D.H., 1991. Geologic map of the Valles Marineris region, Mars. U.S. Geol. Surv. Misc. Invest. Ser. Map I-2010, scale 1:2,000,000. 